\title{
Castillos contra castillos. Padrastros y fortalezas de asedio en la España Medieval
}

\author{
J. Santiago Palacios Ontalva *
}

\begin{abstract}
RESUMEN
El estudio de las capacidades operativas de la arquitectura militar medieval va poniendo de manifiesto que sus posibilidades funcionales son muy amplias, actuando como elementos organizadores del territorio, de sus recursos y de los hombres que lo ocupan; desarrollando unas innegables capacidades simbólicas o representativas; $y$, por supuesto, representando un papel militar del que nunca estuvieron exentas. Un aspecto concreto de esa realidad funcional, sin embargo, nos parece que aún no ha sido estudiado sistemáticamente, nos referimos al hecho frecuente de que algunos castillos se conviertan en herramienta básica para contrarrestar, debilitar y, finalmente, conquistar a otras fortalezas de su entorno más o menos inmediato, sirviendo como recurso de los ejércitos medievales en sus campañas de ocupación y conquista.

En torno a lo que podemos llamar genéricamente fortificaciones de asedio y bloqueo, y en concreto en torno a una tipología específica de ellas que constituyeron los "padrastros" va a girar, por ende, el presente trabajo dedicado a poner de relieve esta parte del protagonismo ofensivo que tuvo la arquitectura militar en diferentes contextos bélicos durante la Edad Media peninsular.
\end{abstract}

PALABRAS CLAVE: Arquitectura militar, Edad Media, Península Ibérica, guerra, fortificaciones de asedio, "padrastros"

\section{INTRODUCCIÓN}

En la dicotomía funcional impuesta entre capacidades defensivas y ofensivas relacionadas con la fortificación medieval, quizás la novedad de los últimos años haya sido precisamente la verificación de numerosos casos en los que la arquitectura castral supera su tradicional papel

\begin{abstract}
The study of the operative capacities of the military architecture of the Middel Ages shows a wide range of their possible functions working as organizing elements of the territory, his resources and his occupying people. They become symbols and represent the military role, which they always had. However, something in their functional reality has not been systematically studied yet; that is the fact that many castles become an essential tool to counteract, weaken and finally conquer another castles and they worked as a resource for the medieval armies in their occupying and conquering campaigns.

This study is focused, in general, on the called castles warfare, to be more precise on a specific kind called "padrastros" (rise in the ground around a castle, fortified or not, that can be occupied by the enemies). This paper pretends to emphasize this offensive role of the military architecture in the Middle Ages in the Iberian Peninsula.
\end{abstract}

KEY WORDS: Military Architecture, Middle Ages, Iberian, war, castle warfare

como elemento defensivo-pasivo, arrogándose además funciones suplementarias de carácter ofensivo hasta entonces algo olvidadas. La exégesis de esta faceta operativa cuenta ya con varios trabajos que ilustran las variadas posibilidades en que se manifiesta esta capacidad de los castillos para intervenir en el contexto bélico desde un punto de vista más activo (GARCíA

\footnotetext{
* Departamento de Historia Antigua, Medieval, Paleografía y Diplomática. Universidad Autónoma de Madrid. Este trabajo forma parte del proyecto de investigación titulado: Poder y organización territorial en el primitivo reino de Toledo, (Ref.: 06/Hse/0009/204), dirigido por Enrique Rodríguez-Picavea Matilla y financiado por la Comunidad de Madrid.
} 
FITZ, 1998a y 1998b), y por tanto, no pretendemos adentrarnos en lo que sería un camino ya transitado. Sin embargo, un aspecto concreto de esa realidad funcional nos parece que aún no ha sido explotado convenientemente, nos referimos al hecho frecuente de que algunos castillos se conviertan en herramienta básica para contrarrestar, debilitar y, finalmente, conquistar a otras fortalezas de su entorno más o menos inmediato, estableciéndose, en consecuencia, un enfrentamiento cuyo desarrollo puede desencadenar actividades y acarrear consecuencias muy diversas. En torno a lo que podemos llamar genéricamente fortificaciones de asedio y bloqueo, y en concreto en torno a una tipología específica de ellas que constituyeron los "padrastros" va a girar, por ende, el presente trabajo dedicado a poner de relieve esta parte del protagonismo ofensivo que tuvo la arquitectura militar en diferentes contextos bélicos del medievo peninsular.

\section{CAPACIDAD OFENSIVA DE LAS FORTALEZAS MEDIEVALES}

Aunque resulta sobradamente demostrado que las fortalezas medievales desarrollaron una multifacética personalidad funcional, si por alguno de estos rasgos prácticos se define con más poder evocador el significado de los castillos y fortificaciones del periodo es, sin duda, por la capacidad militar que fueron capaces de concentrar, orientada tanto en sentido defensivo como proyectada hacia una actividad de marcado acento ofensivo.

Precisamente de este papel agresivo desempeñado por las fortalezas medievales, surge nuestra reflexión, aunque el tema no sea nuevo y ya la historiografía anglosajona asentara hace años unos primeros fundamentos en relación a las fortificaciones cruzadas de Ultramar '. Pues bien, como resulta certificado por una serie de evidencias histórico-arqueológicas, este potencial bélico que atribuimos a los castillos se canalizó hacia objetivos determinados que, en muchas ocasiones, no eran sino otros castillos en poder del enemigo. Se aprecia, por tanto, que las fortalezas actuaron como instrumentos viables para neutralizar la capacidad ofensiva de otros enclaves fuertes, sirviendo de manera individual o colectiva como contrapunto de ciertos enclaves fortificados o conjunto de ellos.

En un escenario militar tan agitado como el ibérico durante buena parte de la Edad Media, y caracterizado, igualmente, por un tipo de guerra de posiciones en la que la conquista de la tierra no se verificaba hasta que todos sus hitos fortificados no estuvieran bajo control, el castillo en sí mismo se convirtió en herramienta imprescindible para la apropiación por asedio de buen número de lugares, capaces de resistir largamente de no emplearse en su conquista la coacción que suponía otro propugnáculo cercano. Como justifica un clásico historiador de la guerra medieval, Ch. Oman, hasta el empleo de la artillería pirobalística la superioridad de la estrategia defensiva que protagonizaban las fortalezas dispersas en el territorio fue el recurso principal al que se enfrentaba una fuerza hostil empeñada en la conquista de cualquier plaza fuerte (OMAN, 1924: pp. 52-53). Sólo con la implicación de numerosos efectivos y medios, o mediante la construcción de fortalezas de asedio el objetivo se hacía factible.

Como punto de partida de nuestro relato pongamos de relieve, en primer lugar, la influencia que ciertos factores ejercieron en la forma que definitivamente tuvieron aquellos singulares enfrentamientos entre castillos. Algunos de los condicionantes que fueron capaces de determinar la capacidad militar de las fortalezas medievales en el sentido antagónico que nos interesa señalar fueron: la distancia que sepa-

\footnotetext{
I Conviene remarcar los siguientes nombres: R. Rogers, J. France o M. Keen,. Entre los escasos trabajos dedicados monográficamente a este tipo de fortalezas véase: Le Maho, J. (1992): "Fortifications de siège et contre-châteaux en Normandie (Xle-Xlle s.)", Château Gaillard, Études de castellologie médiévale. Actes du colloque internacional tenue à Graz (Autriche). XIX. Caen, pp. I8I-I89; Speight, S. (1992): "Castle Warfare in the Gesta Stephani", Château Gaillard, Études de castellologie médiévale. Actes du colloque internacional tenue à Graz (Autriche). XIX. Caen, pp. 269-274.
} 
raba a la fortaleza agresora de su objetivo; la posición topográfica relativa entre ambos enclaves; el diferente tamaño, potencia militar y características arquitectónicas que presentaban; y, por supuesto, la capacidad de unos y otros castillos para funcionar de manera coordinada o aislada, tanto en su faceta atacante como defensiva.

Mediante la exposición de unos pocos episodios bélicos extraídos exclusivamente del contexto hispano, y seleccionados, por supuesto, sin ánimo de exhaustividad ${ }^{2}$, pretendemos ilustrar esta realidad asociada a los castillos y fortalezas medievales de modo que se hagan comprensibles nuestros argumentos y conclusiones a propósito del tema.

\section{Distancia}

Un primer indicador sobre el que recae, en gran medida, la clasificación operativa que proponemos respecto a las fortificaciones de asedio en general, nos viene impuesto por la distancia que separa a las fortalezas implicadas en las diferentes acciones que hemos estudiado. A grandes rasgos se podría anticipar, pues, que serían tres las posibles tipologías en función del espacio interpuesto entre las fortificaciones agresoras y aquellas que constituyeron el objetivo de dichas acciones.

Sólo se podrían considerar en propiedad "castillos padrastro" a los que, emplazados en el perímetro inmediato de la plaza asediada, podían participar en el hostigamiento directo de la misma. Por precisar algo más, esta distancia vendría impuesta por el alcance que pudieran cubrir los proyectiles arrojados desde estos lugares, en principio, de corto alcance y dudoso poder efectivo sobre las sólidas construcciones, pero que más adelante, como sabemos, gracias al eficaz desarrollo tecnológico de la pirobalística, se convertiría en arma determinante de la morfología y capacidad funcional de la arquitectura militar bajomedieval (MORA-FIGUEROA, 1994: pp. 153-154).

En cuanto a la fortalezas levantadas con evidentes intenciones agresivas frente a otras, pero no en el límite de su perímetro sino en su entorno próximo, optamos por considerarlas fortificaciones de asedio, diferentes de los antes definidos padrastros y de otros propugnáculos que basaron su eficacia ofensiva en el mantenimiento de una posición alejada aunque en permanente tensión bélica frente al objetivo. Pues bien, este segundo espectro de enclaves resulta ser el más numeroso, ya que la mayor parte de ellos, sin llegar a erigirse como posiciones de tiro directo frente a otras murallas o sus puertas, sí que contribuyeron eficazmente a cortar las comunicaciones y las líneas de abastecimiento que llegaban a los castillos o ciudades cercadas, albergaban con seguridad a las tropas asaltantes y contribuían, incluso, a formalizar auténticos cierres físicos que aislaban por completo los objetivos.

Si el espacio entre castillos fuera muy dilatado, pero se tuviera constancia de una relación recíproca motivada por la intención de estrangular las comunicaciones y suministros de la plaza hostigada, con motivo de fiscalizar los movimientos de sus habitantes, para procurar inseguridad a los mismos o, en definitiva, para conseguir la capitulación de aquella, estaríamos ante el caso de fortificaciones de bloqueo a distancia, aquellas cuyo objetivo no es inmediato, pero que se sabe o se interpreta que contribuyeron en diferente medida a la conquista de cierto enclave fortificado.

Así pues, entre las pocas decenas de metros que podían separar a un padrastro de un castillo asediado, y los kilómetros de distancia que solían interponerse entre las fortalezas de blo-

2 Reiteramos que no ha sido nuestra intención buscar de manera metódica las referencias a este tipo de fortalezas en las fuentes medievales, sino que nos ha movido un afán más didáctico destinado a seleccionar los ejemplos más convenientes a propósito de nuestra argumentación, aunque éstos superara ciertos marcos cronológicos y espaciales. En cualquier caso, la necesidad de acotar el estudio impuso la obligación de prescindir de muchos paralelos extrapeninsulares que, como ocurre en el contexto cruzado, ofrecen innumerables situaciones de gran valor ilustrativo. Véase: PALACIOS ONTALVA, 200I. 
queo y los propugnáculos en referencia a los cuales se construyeron e interaccionan, la variedad de situaciones es importante, aunque lo más habitual era que en aquellas complejas operaciones destinadas a la conquista de posiciones fortificadas enemigas estuvieran implicadas tanto unas como otras fortalezas a lo largo de etapas sucesivas. Desde el hostigamiento de largo alcance, hasta el que ejercería una hueste plantada delante de los muros de una ciudad y parapetada en sus propias construcciones, en virtud de una estrategia de autodefensa, pero también con la evidente intención de esgrimir firmes bases desde las que ejecutar sus planes de conquista ${ }^{3}$.

\section{Posición relativa}

El dominio de la altura constituye otro elemento fundamental genéricamente asociado a las fortificaciones de asedio. El control de las eminencias topográficas que rodeaban un objetivo preocupó, por consiguiente, a los asaltantes, que apreciaban en ese hecho una ventaja poliorcética notable.

Los ejemplos de este tipo son innumerables. Entre los lugares que probablemente ocupó el califa 'Abd al-Rahmān III en el año 93I alrededor de Toledo, además de su conocida "Ciudad de la Victoria", identificada con el paraje de Zalencas (PORRES MARTíN-CLETO, 1971: I, p. 28 y II, pp. 429-430; MOLÉNAT, 1998: .p. 216), pudo encontrarse el llamado cerro del Bu, enclave situado en la orilla izquierda del Tajo desde el que se tiene una completa panorámica de la ciudad y del cercano puente de Alcántara (Muqtabas V: pp. 280 y ss., trad. pp. 212 y ss.). El pequeño otero no tendría mayor capacidad ofensiva que la de servir como atalaya de observación, pero ese fue su valor durante la Edad Media, cuando pudieron haberse construido las estruc- turas defensivas que fueron descubiertas en los años ochenta sobre su superficie (MARTínEZ LILLO, 1988). Durante otra de las campañas de an-Nāsir, en este caso en el asedio del castillo de Monteleón, los hombres del califa ocuparon un monte que, literalmente, "dominaba" la citada fortaleza (Muqtabas V: p. 60, trad. p. 56). Según la Primera Crónica General, por otro lado, el Cid se refugió en un lugar alto cercano a Monreal, desde el que fazie mucho mal a Medina et a Theruel et a las otras villas de aderredor (PCGE: Cap. 857, p. 530). Se trata, probablemente, del episodio de la fortificación del llamado Poyo sobre la villa de Calamocha, campamento fortificado desde el cual el Campeador dominaba la ribera del jiloca desde Daroca hasta las tierras de Albarracín, incluida la antigua vía romana que unía Calatayud y Murviedro-Sagunto ${ }^{4}$. Por último, nos parece igualmente significativo que las operaciones y movimientos previos al encuentro de Las Navas tuvieran como principal objetivo proporcionar posiciones topográficas elevadas para la instalación de seguros campamentos, cifrando dicha ventaja en el valor poliorcético de la altura (HRH: Lib. VIII, Caps. VII-X; PCGE: Caps. 1016-1018, pp. 697-701; GARCíA FITZ, 2005).

En otro sentido, el dominio de la topografía preocupó igualmente a los mismos defensores, obligados a incluir entre sus proyectos constructivos la protección de un recinto principal así como de los puntos circundantes más propicios para la instalación o edificación de una hipotética fortaleza padrastro.

Si eran empleadas torres móviles para acercarse a las murallas de una plaza cercada, éstas debían ser, lógicamente, más altas que los lienzos que trataban de superar, recreciéndose a veces dichos paramentos para impedir que pudiera darse esa posibilidad. Del mismo modo, cuando conocemos la erección de estructuras directamente involucradas en operaciones de

\footnotetext{
3 Respecto a la estrategia combinada que sería necesaria para tomar ciertas fortalezas y ciudades, las Partidas advierten sobre el hecho de que sólo los objetivos más pequeños podían ser asaltados por fuerza, mientras que en torno a las villas más grandes era necesaria la combinación de muchas operaciones no siempre estrictamente militares (Partidas: II, XXIII, XXVI).

4 Según el Poema de Mío Cid: Y fincó en un poyo que es sobre Mont Real / alto es el Poyo, maravilloso e grant, / non teme guerra, sabet, a nulla part (versos 863-865).
} 
asalto a otros castillos, sus arquitecturas se revelan, en ocasiones, especialmente estilizadas - predominan las torres elevadas-, con la intención de ganar altura desde la que dominar su objetivo. Entre los ejemplos que podemos aludir cabe recordar que en el campamento que 'Abd alRahmān III erigió ante Zaragoza en el año 935, además de palacios y edificios, fueron construidos "puntos elevados" para dominar la ciudad $y$, en concreto, su alcazaba, viendo quien entraba y salía, y a los que circulaban por alguna de sus calles (Muqtabas V: p. 359, trad. p. 269; SOUTO, 1987).

Junto al valor que el control de la altura tenía-de importancia poliorcética y visual-, el acceso al agua pudo resultar igualmente motivo de disputa puesto que si se daba la circunstancia de que el propugnáculo asediado carecía de un suministro independiente de su entorno, o si contaba con reservas limitadas y debía procurarse la aguada en algún punto del exterior, esto podía ser un hecho convenientemente explotado por sus asaltantes. La actuación y hostigamiento de corachas, fuentes, pozos o cualesquier otro elemento arquitectónico que facilitara el aprovisionamiento de agua, así como la construcción de algún tipo de estructura sobre un manantial o a orillas de algún cauce con el objetivo de entorpecer aquella actividad, fueron operaciones especialmente valiosas durante ciertos asedios, muchos de los cuales finalizaron como consecuencia de la sed que abatía a los defensores.

La vigilancia y la construcción de una torre de madera/vineam -"mantelete" como traduce M. Pérez González-, a orillas del Tajo para que los musulmanes que ocupaban Oreja tuvieran dificultades en su abastecimiento constituye una buena muestra de lo dicho (Lám. I) ${ }^{5}$. Pero los ejemplos son múltiples también fuera del contexto toledano. Así, durante el asedio de Lerma por parte de Alfonso Xl, el suministro hídrico de la villa se estranguló puesto que se edificaron dos torres en la fuente que la abastecía (Gran Crónica de Alfonso XI: II, Cap. CLXXXII, p. 135). Y entre las operaciones de la campaña de 1489 destinadas a conseguir la capitulación de Baza, a la que nos vamos a referir en detalle más adelante, se llegó a la conclusión de que la resistencia de la villa disminuiría notablemente si se tomaba posesión de la fuente situada en la cuesta de Alobaçén, para lo cual se mandó fazer un castillo de madera, el qual se avía de lleuar por pieças, e armarse bien çerca de aquella cuesta de Alobaçén, e poner en él gente que defendiese a los moros la salida, entretanto que en aquella cuesta se fundava otro castillo de tapias. Conocidos los planes de los cristianos, y sabedores los granadinos del peligro que entrañaba la pérdida del suministro de agua, la primera noche que lo supieron, puesta gente de armas en la delantera, començaron a tapiar, syn que se podiese ver por los del real la obra que facían. E luego por la mañana se vido fecho un çircuyto de tapias, donde pusieron un capitan con ciertos moros para la defender (...) E asy, hedificando en las noches, fizieron un castillo de tapias en aquella cuesta de Alobaçén, de donde defendían su fuente (Crónica de los Reyes Católicos: II, pp. 388-390).

\section{Características arquitectónicas y capacidades funcionales}

En cuanto a los rasgos arquitectónicos y funcionales que caracterizaron a las genéricamente denominadas fortalezas de asedio, es necesario establecer una nueva distinción entre aquellas directamente implicadas en el hostigamiento del objetivo, obras muy determinadas por la función a desarrollar, y aquellas otras cuya actuación a distancia no implicaba transformaciones formales demasiado específicas.

Pues bien, de entre el primero de los grupos establecidos, una serie de elementos morfológicos se convierten en herramientas frecuentes, registradas incluso en algunos tes5 Interea, imperator iussit poni custodias per ripam fluminis, ne Sarraceni haurirent aquam, ut siti eos perderet, et posuerunt vineam super
quemdam locum ubi occulte hauriebant aquam (CAl: Lib. II, $\mathrm{n}^{\circ} \mathrm{I5I}$ ) 
timonios clásicos de la historia de los asedios, como el caso de las operaciones contra la ciudad etrusca de Veyes, narrada por Tito Livio en su libro quinto de la Historia de Roma, en cuya consecución fueron necesarias complejas operaciones militares y constructivas según va enumerando Apio Claudio en un discurso ante los tribunos de la plebe ${ }^{6}$. Fosos, cárcavas, empalizadas y todo tipo de obras castrales, que hemos de suponer no fueron sino pequeñas torres distribuidas a lo largo de la línea de circunvalación, serían los elementos más característicos.

Durante los siglos medievales, muchos de los citados medios arquitectónicos o castrales empleados para el asedio de otras fortificaciones, destinados a impedir el libre tránsito de los defensores de una posición asediada, o levantados para cortar sus comunicaciones y la posibilidad de recibir ayuda desde el exterior, forman parte de las operaciones normales en los planificados asedios. En las Partidas, por ejemplo, se advierte a los alcaides de castillos de los medios que debían emplear para defenderse de quienes pretendieran asediarles con engeños, cavas o a través de cualquier otra manera de combatir contra los castillos (Partidas: II, XVIII, XI). Mucho antes, en el 890, un miembro de los Banū Qasī, asedió la ciudad de Zaragoza levantando una muralla (sūr) alrededor (Kitāb Tarsï' al-ajbär : p. 36, trad. § 59).

Estas prácticas se perfeccionarán hasta el extremo que se manifiesta durante la guerra de Granada, cuando en torno a la ciudad de Baza se establece un cerco para el que se desplegaron una serie de recursos inimaginables cuyo origen, como hemos visto, se remonta incluso a época romana (Lám. II). En primera instancia se tomaron las fortalezas de Froyla y Vacos en las cercanías de la ciudad, a lo que sucedió la instalación del real en su huer- ta. Vistas las dificultades de concluir con éxito aquella intentona, se trasladó el campamento fuera de la huerta, se optó por levantar el cerco y se pusieron guarniciones en las fortalezas que estauan en çircuyto de la çibdad para guerrear contra ella a distancia. Durante el cerco definitivo, dos campamentos fueron instalados al noroeste y suroeste de la ciudad respectivamente, la huerta fue talada y entre los dos reales se hizo una gran cava e en esta cava se fizo una gran palizada con los árboles de la huerta que fueron talados, e por más la fortificar, mandó el Rey traer las aguas que desçendían de la syerra para que corriesen por medio della. Allende désto, porque tomaua çircuyto de una legua, y era neçesario copia de gente para la guardar, mandó edificar en ella quinze castillos de tapias, con sus torres e almenas, do estoviesen las gentes que la guardasen. Estos castillos están derramados por la cava, e podía aver de castillo a castillo trezientos pasos.(...) Con esta cava e palizada, que llegaua de un real a otro, en la que estauan fabricados estos quinze castillos, la çibdat estaua çercada toda por la parte de lo llano, que ninguno podía en ella entrar ni salir. E por la parte de la sierra mandó el Rey facer otro castillo... Pese a estas magníficas obras y a las guardas establecidas entre la ciudad y la cava perimetral, los moros tenían libertad de movimientos por la parte más escarpada de las montañas, por lo cual ordenó el rey que se fiçiese una cava e palizada, que se consiguiese con la otra que estaua fecha en lo llano, e subiese la sierra arriba, e çercase la çibdat por aquella parte de lo alto, como estaua de parte de lo llano; de manera que ni los moros podiesen salir de aquel çircuyto afuera, ni otros pudiesen entrar en la çibdat a los socorrer (...) Esta cava tomaua en çircuyto de la sierra andadura de dos leguas; en la que convino facer dos grandes e muy anchas paredes, fortificadas con tierra, e piedras, e madera; e entre estas dos paredes avía una calle de cuatro pasos de ancho, a fin que la gente que estouiese en esta calle tovie-

\footnotetext{
6 Sus palabras fueron estas: [los soldados] Hicieron una empalizada (vallum) y una zanja (fossam), trabajos ambos enormemente laboriosos, a lo largo de tan gran trecho; construyeron fortines (castella), pocos en un principio, muy abundantes después al incrementarse los efectivos; levantaron fortificaciones (munitiones) mirando no sólo a la ciudad sino a Etruria, por si llegan refuerzos de allí; ¿para que hablar de las torres (turres), manteletes (vineas) y tortugas (testudines), y demás aparatos de asedio de las ciudades?... (TITO LIVIO, Historia de Roma, $\vee, 5-7)$.
} 
se la una pared por defensa contra los moros que quisiesen salir de la çibdat, e la otra pared contra otros qualesquier que quisiesen venir de fuera a les socorrer (Crónica de los Reyes Católicos: II, pp. 370, 380-38I, 384-388; MIGUEL MORA, 2000).

Los citados elementos arquitectónicos determinaron, en consecuencia, la morfología de las obras castrales de asedio, que podían constituir desde simples empalizadas y fosos dispuestos alrededor de la posición asediada formando líneas de contravalación y circunvalación (VIOLLET-LE-DUC, 1924: III, p. 25 I), hasta pequeños castillos levantados con técnicas rápidas y sencillas como el tapial ${ }^{7}$, torres para reforzar el perímetro, campamentos más o menos fortificados donde alojar las tropas, e incluso ciudades completas, normalmente desarrolladas a partir de instalaciones provisionales que, además de levantarse para combatir una ciudad sitiada y protegerse contra las reacciones de sus defensores, mostraban a éstos -y ése era en muchos casos su fin primordial- la voluntad decidida de prolongar indefinidamente el asedio hasta la rendición (TORRES BALBÁS, 1985: p. 54).

Estas ciudades de asedio, normalmente de vida efímera, llegaron a proporcionar a sus habitantes casi los mismos servicios o comodidades que cualquier otra. Así, por ejemplo, en el campamento de 'Abd al-Rahmān III frente a Zaragoza, llamado al-Yazira y levantado en el año 935, junto a las obras propiamente castrales, la crónica áulica hace referencia a palacios y amplios edificios residenciales para los miembros más distinguidos del cortejo califal, constatando además la instalación de un mercado permanente abastecido por rutas comerciales de largo alcance previamente aseguradas (MUQTABAS V: pp. 359-365, trad. pp. 269273). Contra Toledo fue edificada igualmente una auténtica ciudad, Madīnat al-Fath o "Ciudad de la Victoria", cuyo origen era un "campamento urbanizado"'/mahalla mumaddana, en el que pronto surgieron edificaciones, defensas y mercados para abastecerla (Muqtabas V: pp. 282-287, trad. pp. 213-216). Sin embargo, pese a los ilustrativos textos traídos a colación, con buen criterio J. A. Souto introduce un elemento de reflexión entorno a estas obras, desde su punto de vista, magnificadas considerablemente, entre otras razones, porque esa era la forma más frecuente de que un cronista se ganara el favor de su señor (SOUTO, 1987). Se puede concluir, por tanto, en línea con lo manifestado por el citado arabista y arqueólogo, que más que estructuras de obra, en las llamadas ciudades de asedio se pudieron construir cómodas tiendas y pabellones, desde luego más espaciosas y habitables que las normalmente usadas en campaña, mezcladas con alguna edificación en tapial o madera, de fácil y rápida erección, destinadas, probablemente, a la defensa del perímetro o los accesos a la ciudad-campamento.

Precisamente, otro de los elementos más característicos desde el punto de vista arquitectónico de las obras de asedio, fue su limitada pervivencia temporal y su efímera utilidad, ya que eran levantadas con un objetivo concreto respecto al que, una vez alcanzado, dejaban de tener vigencia práctica. Materiales como la madera, que las Partidas recomiendan formara parte del equipo que todo contingente de asedio debía llevar consigo ${ }^{8}$, y técnicas como el encofrado de tapial, se convirtieron, pues, en herramientas eficaces con las que dotar de defensas una determinada posición dada la celeridad con la que podían ser usadas y la escasa cualificación técnica requerida para su empleo.

7 Volviendo a una de las definiciones del diccionario de Viollet-le-Duc: On désignait aussi par le mot châtelet, des ouvrages de bois et de terre que les assiégeants élevaient de distance en distance entre les lignes de contrevallation et de circonvallation, pour appuyer les postes destinés à garder ces lignes (VIOLLET-LE-DUC, 1924: III, p. 193).

8 Et si sopieren ante que muevan que en el logar do quieren ir non ha abondo de madera con que puedan todas estas cosas sobredichas facer [todo tipo de maquinas de asedio y engeños], débenla levar consigo, ó desque fueren allá ir por ella al logar do entendieren que la podrán mas acerca fallar. Et en esto non debenrezelar trabajo nin costa que fagan, pues que por ello pueden acabar lo que quieren (Partidas: II, XXIII, XXIV). 
Del mismo modo, fue relativamente frecuente que, precisamente para economizar tiempo y recursos, los asaltantes de una plaza fuerte tomaran como base para sus operaciones los restos de alguna estructura preexistente ubicada en las proximidades de las defensas que pretendían violentar. Es el caso del campamento omeya de Talyayra, establecido delante de Bobastro, que fue erigido sobre un antiguo hisn, y donde permaneció an-Nāsir hasta que estuvo levantada una inhiesta fortaleza, donde emplazó a Sa'íd b. al-Mundir al-Qurasi para que hostigara al maldito Hafs y a los suyos, acogidos a la inexpugnabilidad de su bastión (Muqtabas V: p. 211, trad. p. 163).

Otro ejemplo ilustrativo lo constituye el castillo de San Servando (Lám. I0), sobre las colinas que dominan el puente de Alcántara de Toledo, que en realidad se trataba de un primitivo monasterio, pero que, dada su situación extramuros y su posible empleo contra la propia ciudad, pronto se decide fortificar (GONZÁLEZ, I975: II, pp. 76 y 94; ANALES TOLEDANOS: p. 75). Pese a estas obras, y a los diferentes encargados de la custodia de tal lugar ${ }^{9}$, su privilegiada posición frente a uno de los principales accesos a la ciudad hizo de su emplazamiento un deseado objeto por el que se pugnó en repetidas ocasiones. Así, durante el segundo de los asaltos que sufrió Toledo de parte de los almorávides - 1097-, éstos Destruxerunt tamen unam turrem, quae stabat a facie Sancti Servandi, quae erat vigilia, et perierunt in illa quator animae christianorum (CAl: Lib. II, no I 49). Sólo dos años después, en 1099, la ciudad sufría otro embate magrebí con la participación de varios notables almorávides. En esta ocasión,
Yahya ibn Yusūf ibn Tašfin que comandaba la algarada, volvió a instalar su campamento junto a San Servando ${ }^{10}$, pero de nuevo las defensas dispuestas en torno a Toledo resistieron.

\section{TÉCNICAS Y OPERACIONES DE HOSTIGAMIENTO}

Los factores expuestos en las páginas precedentes marcan una serie de diferencias que nos invitan a clasificar los modos en que tuvieron lugar los enfrentamientos entre los genéricamente llamados castillos de asedio y sus objetivos; operaciones diferenciadas por los parámetros técnicos y arquitectónicos que caracterizaban a unas fortalezas de otras, por las capacidades que ambas pudieron ostentar, pero sobre todo por la distancia y relativa posición que sendos propugnáculos ocuparon en el terreno.

\section{Padrastros 11}

Los padrastros o castillos y torres de "mal vecino", según la elocuente terminología de la época ${ }^{12}$, fueron, como ya sabemos, aquellas fortalezas situadas en el contorno inmediato del objetivo que se pretendía hostigar, de manera que sólo aquellas posiciones situadas a la distancia que podía cubrir un proyectil podían ser consideradas en puridad padrastros. Esta definición, sin embargo, es demasiado estrecha y su mantenimiento dejaría fuera algunos buenos ejemplos de castillos destinados a establecer un cerco agresivo sobre otros que superan esa teórica separación. Por este motivo

\footnotetext{
9 Respecto al antiguo monasterio que J. Porres sitúa a unos 200 m. de la actual fortaleza (PORRES MARTíN-CLETO, I993: p. 7I), el II de marzo de 1088, Alfonso VI se lo entregaba a la abadía de San Víctor de Marsella (FITA COLOMER, 1906: pp. 28I-283), encomienda que parece no fue próspera si tenemos en cuenta que, en virtud de la jurisdicción que el arzobispo toledano disfrutaba sobre todos los monasterios de la ciudad, la reina doña Urraca, con el beneplácito de Alvar Fáñez, donaba dicha institución a la propia Iglesia toledana el 19 de marzo de III3 (FITA COLOMER, 1906: pp. 492-500).

I0 Poso Almoarvet Yaya, nieto de Jucaf, fillo de Texefin, en Sant Servando sobre Toledo... (Anales Toledanos: I, p. 385).

I I Muchos de los ejemplos que a continuación expondremos han sido proporcionados en diferentes ocasiones y charlas por dos personas a las que me unen lazos de amistad y profundo respeto profesional, Enrique Varela Agüí y Edward Cooper. A ellos les agradezco sus apreciaciones respecto al tema de los padrastros, tanto como los buenos ratos pasados juntos contemplando castillos.

12 En el caso de Alcalá de Henares, un cerro próximo a la fortaleza de Alcalá la Vieja se denomina de Malvecino. En otros casos como Atienza, el nombre que reciben la eminencias montañosas cercanas a la posición principal se llaman directamente Padrastros.
} 
creemos que dicho criterio de distancia ha de ampliarse o tomarse en cuenta con flexibilidad, aunque sin perder, claro está, la referencia y la perspectiva amenazadora que debía suponer para una fortaleza la presencia próxima de otra orientada a servir como herramienta de expugnación.

Julio César durante el asedio de Marsella ya nos ofrece el exhaustivo relato de la construcción de una torre de asedio pegada a las murallas de la ciudad que, prescindiendo de la complejidad técnica de las operaciones llevadas a cabo para ir levantando la torre poco a poco bajo la protección de una cubierta móvil que se iba elevando a medida que crecía su fábrica, constituye un ejemplo magnífico de la operatividad de este tipo de estructuras castrales destinadas al asedio de otras plazas fuertes: Los soldados legionarios que trabajaban en el lado derecho de la fortificación advirtieron, a causa de frecuentes salidas del enemigo, que podía servirles de gran defensa si construían junto al muro una torre de ladrillo a modo de fuerte y refugio. Primeramente la hicieron pequeña y baja contra los ataques repentinos. Allí se refugiaban; desde allí se defendían si les atacaba fuerzas mayores; desde allí partían para rechazar y perseguir al enemigo. Esta torre tenía treinta pies de lado, pero el espesor de las paredes era de cinco pies (Guerra Civil, II, VIII).

Dentro del ámbito cultural árabo-islámico llama la atención que la raíz ḩšr cuyo significado se mueve en torno a conceptos como "rodear", "encerrar", "bloquear" e incluso "asediar un lugar" sirva, por extensión, para referirse a una fortaleza o lugar fortificado desde el que se pueden ejercer dichas acciones, y que dicho término forme parte de buen núme- ro de topónimos localizados en su mayoría en Asia Menor ${ }^{13}$.

Pero centremos nuestros argumentos en el empleo de este tipo de fortificaciones durante algunas operaciones de conquista acontecidas en el contexto bélico peninsular durante el siglo XII. Nos referiremos en primer lugar a la conocida plaza de Mora (Láms. 5-8), que tras ser arrebatada en I I 38 a su alcaide, Munio Alfonso, se convirtió en base de numerosos ataques musulmanes que azotaron la cercana tierra de Toledo (CAl: Lib. II, no |4|-142). Pues bien, ante la amenaza real que constituía el enclave, Alfonso VII ordenó la construcción de un nuevo castillo junto a Mora la vieja, la llamada fortaleza de Peña Negra, que fue entregada a Martín Fernández, y cuya misión consistía en limitar la capacidad de maniobra y agresión de la guarnición de aquella ${ }^{14}$.

El objetivo parece que se cumplió puesto que inmediatamente el llamado princeps de Calatrava, el adalid Farax, reunía un heterogéneo contingente de guerreros procedentes de todas las ciudades andalusíes hasta el río Guadalquivir, internándose en tierras toledanas con la intención de munirent castellum quod dicitur Mora (CAl, Lib. II, $n^{\circ}$ 178). Poco después, pese a estos esfuerzos musulmanes y pese a la derrota del afamado caudillo Munio Alfonso (CAl, Lib. II, n० |8I), en abril de II44 la propia fortaleza de Mora sucumbió al asalto del Emperador (Anales Toledanos: I, p. 389), ayudado, a buen seguro, por la presencia amenazadora del padrastro de Peña Cristiana.

Una vez en poder cristiano, al menos, hasta 1224 parece que ambas estructuras castrales convivieron en sus emplazamientos respecti-

13 Entre las muchas fortalezas citadas cuyo nombre contiene la raíz árabe Hašara en su forma Hišār, se encuentran dos que participaron en diferentes tentativas de asedio de Constantinopla. Ambas se encuentran en la parte más estrecha del Bósforo y fueron erigidas para impedir el tránsito de barcos por dicho canal natural: en el lado asiático el sultán Bayazid I levantó el castillo de Anadolu Hišăr en 1395, mientras que en el lado europeo fue Mehmmed II quien hizo lo propio en I 452 con la fortaleza llamada Rumeli Hišăr (The Enciclopedia of Islam, 1979: vol. III, p. 469).

14 La Crónica del Emperador lo relata de la siguiente manera: Imperator vero, audiens quod capta esset Mora, abiit illuc et fabricavit contra faciem Morae aliud castellum quod dicitur Penna Nigra, melius et fortius, et munivit illum militibus et peditibus multum bellicosis et sumptibus; et dedit illum cuidam principi, cuius nomen erat Martinum Fernandi, qui quotidie debellabat eos, qui erant in Mora, usque imperator cepit eum (CAl: Lib. II, nº |43). J. González por su parte, cita un documento de II 43 que conmemora el día que se sitió la fortaleza de Mora gracias a la construcción del padrastro de Peña Negra (GONZÁLEZ, 1975: I, p. 146). 
vos, ya que en esa fecha Fernando III ordenaba la destrucción de illas turres de Rupe nigra in colle de Mora considerando que podían suponer un peligro para el castillo primitivo (GONZÁLEZ, 1980: III, doc. nº 192, p. 233).

Del análisis de los datos expuestos sobre los castillos de Mora y Mora la vieja, tal y como figuran en documentos posteriores - véase la primera bula de confirmación concedida a la orden de Santiago en II 75 (MARTíN, 1974: doc. n 73, pp. 248-254)-, se desprenden, sin embargo, algunas dudas que no nos sentimos capaces de resolver satisfactoriamente: en primer lugar, parece un tanto inverosímil que los escasos restos que se conservan en las proximidades del actual castillo correspondieran en algún momento a un enclave que las fuentes calificaron de melius et fortius. Además, si el papa Alejandro III confirmaba, entre otras muchas, las dos posesiones citadas, por qué en la concesión a la orden de Santiago de la fortaleza hecha en I I7I todo parece indicar la existencia de una sola de ellas (MARTíN, 1974: doc. n 45, pp. 217-218), y sobre todo, por qué años más tarde - II80Alfonso VIII entregó de nuevo a la orden un castillo llamado de Peña Negra, que se suponía en su poder ya en II 75 (MARTíN, 1974: doc. no I I 3, pp. 297-298). Además si Fernando III ordena la destrucción de ese castillo, por qué todavía son visibles restos que parecen haberse deteriorado exclusivamente por causas naturales.

Una vez descartado que el primitivo asentamiento de Mora -Mora la vieja- estuviera en el llano que ocupa la población actual, y que el padrastro se levantara donde hoy se encuentra el castillo, recientemente se ha vuelto a plantear la identificación, sin ningún género de dudas, del padrastro de Peña Negra o Peña Cristiana, con los restos todavía visibles sobre el farallón rocoso que, a una cota de 967 m., se eleva al sur de la fortaleza principal (IGLESIAS PICAZO, RETUERCE VELASCO, 2005). Tal planteamiento parecería el más lógico dada la posición relativa de ambos propugnáculos -éste a mayor cota que aquel-, así como la distancia entre ellos, -alejados apenas por unas decenas de metros-, sin embargo, atendiendo a otros indicios, como su respectiva materialidad arquitectónica, no creemos razonable que este padrastro se considerara un edificio mejor y más fuerte que el castillo de Mora, a no ser que la crónica donde aparece la noticia transmita una visión idealizada o exagerada de la capacidad ofensiva que Peña Negra tenía. En el mismo sentido, la distancia que se cree existía entre ambos enclaves era de media legua -más de 2,5 Km.-, por lo que el referido padrastro pudo haberse erigido en alguna de las eminencias montañosas que se extienden en el sector sureste de la fortaleza principal, tal y como propone J. González, que la emplaza sobre el cerro del Buey (GONZÁLEZ, 1975: I, p. I46). Sobre estos montes pudo haberse construido, en consecuencia, una fortaleza destinada al asedio de Mora cuya fecha de inicio sabemos con precisión - I I43-, perteneciendo los restos cercanos, que Retuerce identifica con el padrastro, o bien a obras islámicas destinadas a la defensa de los aproches que pudieron haberse ejecutado por las tropas de Farax cuando llegaron a la plaza para reforzarla ante la presencia cercana de los cristianos, o bien ser fábrica posterior a la reconquista del enclave ${ }^{15}$.

Sea como fuere, el caso del padrastro de Mora no es el único, y podemos encontrar nuevos paralelos de fortalezas concebidas para la conquista de otras sin salirnos siquiera de los señoríos toledanos de la orden de Santiago, institución a la que también perteneció el enclave de Oreja por el que ahora nos interesamos (Láms I-3).

\footnotetext{
I5 El modo en el que creemos que se llegan a explicar en un discurso coherente los interrogantes textuales, tanto documentales como cronísticos, y las evidencias arqueológicas, pasa por considerar que el castillo de Mora estaba formado por los restos de la actual fortaleza y por los que se ubican en el llamado cerro de Malvecino, mientras que el desaparecido padrastro ocuparía una posición cercana pero desconocida por el momento. Así se explica que, pese a que desde I I 7 I el castro de Mora era propiedad santiaguista y a que la bula de confirmación del papa Alejandro III incluye los topónimos de Mora y Mora la Vieja entre los señoríos de la orden de Santiago, en I I 80 se verifique la entrega a la institución del verdadero padrastro de Peña Negra.
} 
Este castillo ubicado en la ribera del río Tajo, tras una campaña narrada en detalle en la Chronica Adefonsi Imperatoris y cuyas consecuencias político-territoriales resultaron sumamente relevantes ${ }^{16}$, fue finalmente recuperado por las tropas castellano-leonesas a finales de octubre de II 39 (CAl: Lib. II, no |54). Pero a lo largo del dilatado cerco que sufrió la plaza, nos llama la atención un hecho que prácticamente ha pasado desapercibido, nos referimos a la noticia de la construcción de un castillo en el entorno inmediato a Oreja destinado al hostigamiento permanente del recinto principal, y por tanto con evidentes características ofensivas. De la existencia de este enclave sabemos por ser el lugar desde el que Alfonso VII despacha algunos documentos entre julio y septiembre de I 139, in illo castello novo quod fecit imperator predictus iuxta Aureliam quando eam tenebat obsesam ${ }^{17}$.

Es decir, estaríamos hablando de la posible presencia de un padrastro o de algún tipo de fortaleza de asedio acerca de la que, en su día, hizo P. Madoz una escueta referencia cuando menciona la existencia en Oreja de dos castillos, uno conservado y otro destruido (MADOZ, 1950: XII, p. 302). Pues bien, este propugnáculo pudo haberse situado donde actualmente se encuentra la ermita y los restos más modernos de edificaciones, a unos doscientos metros del castillo en dirección este-sureste; o bien en la cima de otro cerro situado al suroeste de la fortaleza principal, sobre el que hemos podido constatar la presencia de restos constructivos, de cerámica medieval, e incluso de lo que pudieron ser algunas estructuras como un foso y los arranques de muros de tapial prácticamente arrasados. La acción combinada de los asaltantes y de sus máquinas de guerra, junto a la interrupción del suministro de agua que éstos trataron de conseguir $y$, por supuesto, gracias a la presencia intimidatoria de un padrastro a la vista de los defensores, fueron los resortes inmediatos que hicieron capitular la plaza.

Otros autores han glosado ya algunos ejemplos más de este tipo de fortificaciones de asedio, son los casos de Castilnovo contra Molina, Calatrava la Nueva frente a Salvatierra (Lám 9), San Pablo contra Montiel ${ }^{18}$, además de los casos citados de Mora y Oreja, que menciona J. González (GONZÁLEZ, 1975: I, pp. 285 y 354-355; GONZÁLEZ, 1975: II, pp. 201-202; RODRÍGUEZ PICAVEA, 1994: p. 104), o la posibilidad de que el castillo de Miraflores fuera levantado como padrastro del de Piedrabuena, como sugirió Corchado (CORCHADO SORIANO, 1982: pp. 37 y y 377). Sin embargo los ejemplos se pueden multiplicar con una simple lectura detenida de las crónicas medievales, y así aparecen más casos como el de Alcalá de Henares (Lám. 4), conquistada en III8 por el arzobispo de Toledo, quien había ordenado la construcción de una fortaleza sobre una colina que dominaba el emplazamiento islámico (HRH: Lib. VI, Cap. XXVIII; PCGE: Cap. 875, p. 546); o el castillo de Belillos, fortaleza levantada por castellanos y sevillanos aliados frente al reino de Granada y que, según el traidor granadino Ibn Adhà, era idónea para hostigar y apremiar con más eficacia a la capital zirí (Las "Memorias" de 'Abd Alläh: pp. 153-156).

16 Oreja se había destacado entre los años II I 3 y II 39 como base de operaciones para los contingentes almorávides que acosaban Toledo. Su conquista se convirtió entonces en el primer triunfo de las armas cristianas en el Tajo, y en punto de inflexión a partir del que se alejó definitivamente la frontera de las márgenes de este río.

17 Cit. GONZÁLEZ, 1975: I, nota n 9, p. 142. Además de los documentos de 25 de julio, 13 de agosto y 7 de septiembre de I I39, se puede añadir otro de 18 de octubre del mismo año, también otorgado iuxta Aureliam, in ipso Castello Nouo, quod ibi fecit imperator quando eam tenebat obsessam (RASSOW, 1929: doc. $n^{\circ}$ 14, pp. 80-81).

18 No tenemos evidencias de que el castillo de San Pablo hubiera ejercido como padrastro del castillo de la Estrella o de Montiel, ni siquiera durante el más famoso de los episodios en los que se vieron envueltos. Nos referimos a la muerte de Pedro I a manos de su hermanastro, Enrique de Trastámara. Sin embargo, en el trascurso de las operaciones que condujeron al asedio del rey en la fortaleza de Montiel, encontramos el siguiente pasaje: El rrey don Enrique desque ovo desbaratado la dicha pelea de Montiel e vio al rrey don Pedro acogido al castillo que y era puso muy grand acuçia en fazer cercar de piedra seca [faziendo] una pared al lugar de Montiel [enderredor] por rreçelo que el rrey don Pedro non se fuesse de ally. E asy fizo e puso muy grandes guardas de dia e de noche enderredor del lugar...(Crónica del rey don Pedro y del rey don Enrique: vol II, cap. VIII, p. 286). 
Esta reiteración con la que aparecen casos similares en la documentación del momento nos lleva a creer que, como en otros ámbitos extrapeninsulares, en la realidad castral hispana se insertó, entre las funciones que con cierta normalidad desempeñaron los castillos, este papel ofensivo orientado hacia la conquista de otros puntos fuertes a través precisamente de la potencia agresiva que se podía desplegar desde ellos.

\section{Castillos de asedio}

Ante la evidente dificultad que plantea establecer un criterio de distancia para diferenciar entre castillos de asedio y fortificaciones de bloqueo, dada la relatividad de las dimensiones y la diferente capacidad de interaccionar unas fortalezas sobre otras, proponemos introducir otros factores de clasificación para hacer viable y comprensible la división esbozada. Así pues, no sólo la distancia al objetivo, sino la entidad del mismo o el tiempo empleado para su conquista se pueden tener en cuenta, ya que es lógico creer que las más importantes ciudades sólo sucumbirían después de operaciones más complejas y extensas que las desarrolladas alrededor de propugnáculos de menor categoría. De este modo, delante de plazas pequeñas o medianas el empleo de padrastros sería una táctica eficaz, o al menos suficiente, mientras que las grandes ciudades o las posiciones más fuertes y relevantes precisaban de una estrategia de mayor profundidad a la que se añadía el hostigamiento a distancia o el bloqueo de sus comunicaciones que sólo podían proporcionar enclaves situados en un perímetro más alejado ${ }^{19}$.

Las Partidas recomiendan a las huestes asaltantes que tomen las posadas en derredor de aquel logar que quieren cercar (...) et si toda non la pudieren cercar deben posar á compañas ante las puertas porque le tuelgan entrada et salida; et sinon todos en uno en el logar do entendieren que mayor daño podrán facer á los de dentro (Partidas: II, XXIII, XXIII). El control de los accesos a una fortaleza, por tanto, suponía el primer objetivo de las fortificaciones de asedio que no se podían emplazar en el perímetro inmediato a la plaza cercada, de manera que, aunque no se hostigara directamente las defensas de ésta, sí se incapacitaran sus vías de comunicación con el exterior, tanto para solicitar o recibir auxilio militar, como para avituallarse.

Sin ser propiamente padrastros, puesto que su radio de acción no alcanzaba directamente a la fortaleza objeto de asedio o su entorno más próximo, existen multitud de casos de lugares sometidos o amenazados por la presencia de otros castillos construidos ex profeso para tal fin. Así, el castillo de Santiesteban, uno de los rebeldes al poder cordobés situado en la cora de Elvira, que junto al hisn llamado de Peña Forata hacían daño a las gentes de la fortaleza de Granada y de la capital, Elvira, fue hostigado literalmente hasta llegar al colmo, gracias a la construcción de seis contrabaluartes -Husūn-, unos frente a otros, donde se instalaron las correspondientes guarniciones, formando como un anillo que los cercaba y estrechaba (Muqtabas V: pp. 67-68 y 200-20I, trad. pp. 62 y 155). Durante las operaciones de asedio a las que fue sometida Valencia en la primavera de 1089 por parte del conde de Barcelona, Berenguer, el rey de Zaragoza al-Musta'în, interesado en hacerse con el poder de la ciudad que gobernaba al-Qādir, apoyó dicha campaña estableciendo contra ella dos fortalezas, una en Liria y otra en el llamado Puig, e incluso proyectaba levantar una tercera en la Albufera para estrangular las comunicacio-

\footnotetext{
19 Recordemos las recomendaciones de las Partidas en este sentido, recogidas en la Ley XXVI de las dedicadas a la guerra: Guardábanse mucho los antiguos de poner engeños sinon á castiello ó á villa pequeña, porque en tales logares facen mayor daño derribando los muros, et las torres et aun las casas, et matando los homes, lo que non podrien facer en las villas grandes: ca estas de lieve nunca se toman sinon por fambre, ó por furto, ó por cavas, ó por feridas de bozones con que derribasen los muros, ó por castiellos de madera que llegasen á las torres con que las entrasen por fuerza, ó por combatirlos tan afincadamente que los subiesen por escaleras: pero tambien los menores logares que dixiemos como estos non se pueden tomar por ninguno destos combatimientos sobredichos, á menos de seer los de fuera muchos et mejores que los de dentro (Partidas: II, XXIII, XXVI).
} 
nes de la capital levantina (MENÉNDEZ PIDAL, 1969: I, pp. 356-357). El asedio de Cuenca, por otro lado, actuación llevada a cabo por Alfonso VIII en I I77, observó también ciertas obras constructivas destinadas al cerco de la inaccesible plaza musulmana. El monarca se entregó a la empresa con gran dedicación et laboribus pluribus arctavit eos: extruxit in gyro plures machinas [bastidas según la Primera Crónica General], nec die, nec nocte pepercit eis ${ }^{20}$, de manera que clausuró las entradas y salidas de la ciudad, hasta que los defensores capitularon, no sin antes haber solicitado infructuosamente el auxilio de los almohades.

Interesa añadir que, además de las puertas y los caminos que constituían los principales objetivos en una operación de cerco, los propugnáculos emplazados a media distancia se encargaban de impedir otros servicios imprescindibles para los defensores, como era el forrajeo de sus bestias o la recolección de sus campos, todo lo cual significaba la práctica destrucción de sus medios de vida (Muqtabas V: p. 211 , trad. p. 163).

\section{Fortificaciones de bloqueo}

Cuando una fortaleza o ciudad que se pretendía expugnar requería no sólo el establecimiento sobre el terreno de posiciones a corta y media distancia, sino un bloqueo a mayor escala, entraron en juego fortificaciones emplazadas, en ocasiones, a considerable distancia de su objetivo, pero integradas en sistemas más o menos bien organizados cuyo fin era la conquista de algún punto fuerte enemigo. Ajenas, por consiguiente, al desarrollo directo de los acontecimientos, que normalmente terminaban con el asalto de la posición asediada desde los propugnáculos situados en el entorno más cercano, las fortalezas de bloqueo básicamente fiscalizaban las comunicaciones de aquella o sus principales fuentes de abastecimiento y de recursos económicos, permaneciendo al margen de las acciones militares definitivas. Pese al papel aparentemente secundario que pudieron jugar, ante grandes ciudades que extendían sus vectores de relación sobre extensos espacios, las plazas a las que nos referimos resultaron necesarias y complementarias de la estrategia global seguida para su definitiva dominación, aunque su presencia no resultara tan amenazadora, en primera instancia, como sí lo eran otros enclaves visibles desde las mismas defensas de las posiciones hostigadas.

En este sentido, de nuevo las campañas desarrolladas por 'Abd al-Rahmān III contra diferentes lugares débilmente sujetos a su autoridad o abiertamente insumisos a ella, podrían ilustrar por sí mismos lo que queremos exponer. Así por ejemplo, el caso del baluarte de Bobastro y las complejas acciones destinadas a su conquista podría suponer un gráfico acercamiento al tema. Veamos porqué:

Bobastro, acerca de cuya inexpugnabilidad se hacen permanentes referencias, sin duda para exagerar el valor mismo que otorgaba al califa la conquista de un enclave $\tan$ bien y celosamente protegido, era la residencia del rebelde cristiano "Umar ibn Hafsūn y el lugar, junto con otras posiciones, desde las que éste se dedicaba a desestabilizar, con su actitud y sus actividades bélicas, una parte importante del califato cordobés (MARTíNEZ ENAMORADO, 1996). Pues bien, en el largo proceso que condujo a la conquista de la plaza, entre julio del año 922 y mayo de 927, diferentes tipos de fortificaciones fueron construidas u ocupadas con el objetivo de hacer sucumbir el propugnáculo hafsasí. En 922, en el curso de una larga expedición por las coras de Elvira, Riyya y Takurunnā, además de arrasar las tierras próximas a la fortaleza de Bobastro, estableció a varios caídes en los contrabaluartes que contra ellos

20 HRH: Lib. VII, Cap. XXVI; PCGE: Cap. 999, p. 679. Llama la atención, en este caso, la identificación de las machinas y las bastidas que se establece entre ambas crónicas, paralelismos que no siempre están claros puesto que en otros textos las bastidas se asimilan probablemente a obras terreras destinadas a la protección de los asaltantes o de su campamento. 
[contra los disidentes] había hecho (Muqtabas V: p. 180, trad. p. 140). En abril de 923, otra nueva campaña es dirigida por an-Nāsir contra los rebeldes, durante la cual ocupa numerosas fortalezas que protegían los alrededores del baluarte cristiano, tomando con ello también los castillos integrados en sus respectivos territorios castrales. Tras establecer en algunas de ellas guarniciones, procedió otra vez a reforzar con caballería los contrabaluartes más próximos a Bobastro (Muqtabas V: pp. 183-185, trad. pp. 142-143). En la primavera de 927, el califa encabezaba otra expedición contra la ciudad de perdición y nido de hipocresía, dedicado igualmente a conquistar más fortalezas de las dependientes de Bobastro que, como en el caso de Olías, destruiría casi por completo, dejando sólo en pie su alcazaba para que le sirviera como lanzadera de un posible asalto contra la capital. Reforzó, asimismo, los contrabaluartes, que parece consideraba la cosa más dañina contra los prevaricadores; ordenó la construcción de una nueva fortaleza en la peña conocida como al-Madina, desde la que dominaba todos los caminos de la ciudad del maldito, con lo que podía vigilar a los forrajeadores y encargados de otros servicios o a los que circulaban del ejército en cualquier dirección; y procedió a instalar su campamento/mahalla en Talyayra, donde fue levantado otro hisn, a veces también llamado madina (Muqtabas V: pp. 209-214, trad. pp. 161-164). Finalmente, ibn Hafsūn, rodeado como estaba de construcciones por todos lados, viendo que se le trataba con una firmeza que no le permitía permanecer en el risco en que se asía, donde le eran vedados los medios de vida, solicitó del califa amán y perdón para concluir con aquel episodio (Muqtabas V: pp. 212-213, trad. p. 164).

Entre 931 y 932, Toledo fue, a su vez, el nuevo objetivo de las armas califales, empeñadas en someter la insurrecta capital de la Marca Media. En esta empresa, además de la ya citada ciudad de asedio erigida por an-Nāsir, Madīnat al-Fath o "Ciudad de la Victoria", que no debía ser sino un simple campamento urbanizado en el que pronto se levantaron edificaciones, defensas y mercados casi permanentes (Muqtabas V: pp. 282-288, trad. pp. 213-216), a lo largo de los años previos a su definitiva sumisión, la crónica se refiere, sin citar expresamente su nombre, a fortalezas dispuestas alrededor de los toledanos orientadas a inclinar a sus gobernantes al lado del califa (Muqtabas V: pp. 277-278 y 288 , trad. pp. 210 y 216). Como advierte J. A. Souto, el texto de la crónica nada dice acerca de la construcción de nuevas fortalezas, sino de la "disposición" de algunas de ellas en torno a Toledo (SOUTO, 1996: p. 202), dato que podría relacionarse con la política de 'Abd al-Rahmān III respecto a la ciudad y otra serie de enclaves de la Transierra directamente relacionadas y fortificadas por el califa con vistas a conseguir la capitulación de la ciudad tagana. Madrid, Talamanca, Peñafora, Calatrava y Talavera formaría parte, por tanto, de esta red de fortalezas dispuestas por el poder central cordobés para la labor de control antedicha (MANZANO, 1991: pp. 163-171). Estas "sutiles" maniobras del califa, en cualquier caso, no dieron resultado $y$, solo después de que fueran derrotadas las tropas que los aliados de los toledanos habían enviado para levantar el cerco sobre la ciudad, se verificó la rendición de la misma (Muqtabas V: pp. 317-320, trad. pp. 238-240).

La ciudad de Zaragoza supuso, igualmente, una dura prueba para las tropas califales y la puesta en juego de diversos recursos poliorcéticos. Además del mencionado campamento o al-Yazira (SOUTO, 1987) y de varias fortalezas que formaban parte de las defensas de la propia ciudad pero que el avance califal convirtió en bases desde las que hostigar el antiguo centro que protegían -Maluenda, Rueda de Jalón, Arnedo, María, Murillo u Orés, entre ellas-, 'Abd al-Rahmān III estableció a sus caídes en una serie de emplazamientos, bastante alejados de la ciudad, desde los que hostigarla permanentemente. Estas verdaderas fortalezas de asedio a distancia fueron: Tarazona, Tudela, Borja, Huesca y Daroca, entre las que cita el Muqtabas, a las que se sumarían probablemente Calahorra, Caparroso, Falces y Valtierra, situadas las más cercanas a unos $60 \mathrm{Km}$. de la capital, y con las que se formó un verdadero "tapón" para quien, aprovechando este momento de crisis, quisiera penetrar en territorio islámico desde la zona cristiana o desde la parte más septentrional de la Marca Media, así como para cerrar el paso a los musulmanes que desearan huir de la Marca Superior por ese mismo 
camino (SOUTO, 1992: pp. 275-276). Junto a las citadas plazas preexistentes que fueron ocupadas para destruir las defensas y cortocircuitar las principales comunicaciones en el territorio de Zaragoza, a propósito del cerco más inmediato de la ciudad también fueron levantadas fortificaciones en los puntos más molestos y pobladas de hombres que los vigilaban y combatían por doquier, de manera que el objetivo se encontraba "estrangulado" (MUQTABAS V: pp. 359-364, trad. pp. 270-272). Entre aquellas fortificaciones expresamente erigidas para el asedio sólo conocemos la de Murbit, identificada por J. A Souto con Cadrete (MUQTABAS V: p. 362, trad. p. 27I; SOUTO, 1996: p. 198). Pero además, estas posiciones califales, y en concreto su campamento de al-Yazira, recibían permanente abastecimiento desde otra serie de lugares adeptos al poder cordobés (Muqtabas V: P. 360, TRAD. p. 269), por lo que en todos los sentidos la ciudad del Ebro parecía abocada a una rápida capitulación. No fue así debido a la intervención de Ramiro II de León en 936, aunque definitivamente la ciudad cayó un año después, llegándose a efectuar desde el campamento del califa un asalto de las murallas de la misma con máquinas de guerra y almajaneques, que constituyó el último episodio de las operaciones del asedio zaragozano.

Por otro lado, el mismo cerco que condujo a las huestes de Alfonso VI a tomar Toledo en 1085, puede analizarse, si se quiere, como un episodio similar a los ya expuestos en cuanto al empleo de la fortificación como herramienta válida para quebrantar la resistencia de una fortaleza a ser conquistada. En primer lugar, con anterioridad al definitivo establecimiento de los castellanos a las puertas de la ciudad, el propio avance reconquistador por las tierras del Tras-Duero, había supuesto la instalación de emplazamientos seguros en lugares como Salamanca, Cuéllar o Sepúlveda. Más adelante, en 1079, en respuesta a la llamada de auxilio que un amenazado al-Qādir le había hecho, Alfon- so $\mathrm{VI}$ entraba en el reino de Toledo por alguno de los pasos occidentales de la Sierra, y desde abril de aquel año intervenía contra el monarca pacense con la intención de reponer en el trono a toledano. La conquista de la fortaleza de Coria hacia septiembre de aquel año, supuso un hecho notable de aquella campaña, así como una adquisición significativa para los planes repobladores alfonsinos (REILLY, 1989: p. 148), pero lo que nos interesa subrayar es el hecho de que esta primera posición estratégica en el Tajo permaneció en poder castellano, y pudo servir como apoyo a la futura conquista de Toledo. Antes de ser repuesto en el trono, en 1081, el rey cristiano exigió la entrega de dos nuevas fortalezas que venían a reforzar su posición alrededor de la capital de los Banū DīI-Nūn (IBN AL-KARDABUS: pp. 103-104): Zorita de los Canes, sobre el curso alto del Tajo y orientada frente a los territorios musulmanes de Zaragoza y Valencia; y Canturias, castillo localizado también en la ribera del Tajo, al oeste de Talavera, con la evidente intención de frenar cualquier avance musulmán desde el reino aftasí de Badajoz. Abastecidas y guarnecidas estas plazas, el cerco sobre la capital de la taifa toledana era inmediatamente completado con la entrega del castillo de Canales, fortaleza que controlaba la importante ruta del río Guadarrama hacia Toledo (HRH: Lib. VI, Cap. XXII). La ciudad quedaba, en consecuencia, aislada por todos sus puntos ${ }^{21}$, excepto el camino meridional hacia Córdoba, y a merced de la voluntad del monarca castellano-leonés, quien contaba con las bases necesarias para hostigar con garantías de éxito las tierras toledanas e incluso sus mismas murallas.

\section{CONCLUSIONES}

Se manifiesta, por tanto, a través de esta selección de episodios y momentos del pasado medieval peninsular el sentido ofensivo que la arquitectura militar fue capaz de desarrollar

21 Zorita de los Canes y, probablemente, Brihuega, cerraba el acceso a Cuenca y Huete e incluso a probables incursiones valencianas o aragonesas. Canturias, Canales y Olmos, junto a Coria, servían para el control del sector occidental del reino, donde la amenaza radicaba en la ciudad de Talavera. 
en sintonía con las funciones defensivas que tradicionalmente se han considerado prioritarias en su esencia práctica. La mera presencia de un propugnáculo en el entorno más o menos inmediato de otro significaba una amenaza potencial que provocaba un latente estado de tensión bélica entre las fortalezas implicadas y que, en ocasiones, desembocó en el enfrentamiento directo de ambas posiciones. En el escenario hispano, tan determinado por un secular estado de conflictividad militar casi permanente, no fue extraño pues que una fortaleza fuera empleada para doblegar la resistencia de otra o que, en cualquier caso, se plantearan frecuentes antagonismos de castillos contra castillos como reflejo de la propia pugna por el dominio político y militar del espacio.

\section{BIBLIOGRAFÍA}

'ABD ALLĀH (1980): El siglo XI en I ${ }^{a}$ persona. Las "Memorias" de "Abd Allāh, último rey Zirí de Granada, destronado por los Almorávides (1090), E. Leví-Provençal y E. García Gómez (Eds.). Madrid.

ALFONSO X (1972): Las siete Partidas del rey Alfonso el Sabio cotejadas con varios códices antiguos por la Real Academia de la Historia, 3 vols. Madrid.

ALFONSO X (1977): Primera Crónica General de España, R. Menéndez Pidal y D. Catalán (Eds.), 2 vols. Madrid.

CATALÁN, D. (Ed.) (1977): Gran Crónica de Alfonso XI, D., 2 vols.. Madrid.

CORCHADO SORIANO, M. (1982-1983-1984): Estudio histórico-económico-jurídico del Campo de Calatrava, 3 vols. Ciudad Real.

FITA COLOMER, F. ( 1906): "El monasterio de San Servando", BRAH. XLVIII. Madrid, pp. 492-500.

GARCÍA FITZ, F. (1998a): Castilla y León frente al Islam. Estrategias de expansión y tácticas militares. Sevilla.

GARCÍA FITZ, F. (1998b): "Pora acreçentamiento de nuestros regnos. Las funciones ofensivas de los castillos de frontera", La Fortaleza Medieval: Realidad y Símbolo. Alicante, pp. 75-89.

GARCÍA FITZ, F. (2005): Las Navas de Tolosa, Barcelona.

GONZÁLEZ, J. (1975): Repoblación de Castilla la Nueva, 2 vols. Madrid.

GONZÁLEZ, J. (1980): Reinado y diplomas de Fernando III, 3 vols. Córdoba.
IBN HAYYĀN (1979): Al-Muqtabas V, P. Chalmeta, F. Corriente, M. Subh y otros (Eds.). Madrid. (198I): Traducción M. J. Viguera y F. Corriente, Zaragoza.

IBN AL-KARDABUS (1993): Historia de al-Andalus (Kitāb al-Iktifä'), F. Maillo Salgado (Ed.). Madrid.

IGLESIAS PICAZO, P.; RETUERCE VELASCO, M. (2005): "Los «castillos» y «palacios» de Mora de Toledo", Espacios fortificados en la provincia de Toledo. Diputación Provincial de Toledo, pp. 293-330.

JIMÉNEZ DE RADA, R. (1989): Historia de los hechos de España, Juan Fernández Valverde (Ed.). Madrid.

LE MAHO, J. (1992): "Fortifications de siège et contrechâteaux en Normandie (Xle-Xlle s.)", Château Gaillard, Études de castellologie médiévale. Actes du colloque internacional tenue à Graz (Autriche). XIX. Caen, pp. |8|-189.

LÓPEZ DE AYALA, P. (1997): Crónica del rey don Pedro y del rey don Enrique, su hermano, hijos del rey don Alfonso Onceno, Germán Orduna (Ed.) Buenos Aires.

MADOZ, P. (1950): Diccionario Geográfico-Estadístico-Histórico de España y sus posesiones de Ultramar. Madrid.

MANZANO, E. (|99|): La frontera de al-Andalus en época de los Omeyas. Madrid.

MARTíN, J.L. (1974): Orígenes de la Orden Militar de Santiago (I I 70-1 I 95). Barcelona.

MARTÍNEZ ENAMORADO, V. (1996): "Algunas consideraciones espaciales y topográficas sobre Bobastro", AlQantara. Vol. XVII. Madrid, pp. 59-77.

MARTÍNEZ LILLO, S. (1988): "El hábitat islámico del cerro del Bu (Toledo): primeros resultados arqueológicos", Actas del I Congreso de Historia de Castilla-La Mancha. Vol. V. Junta de Comunidades de Castilla-La Mancha, pp. $105-1 \mid 6$.

MENÉNDEZ PIDAL, R. (1969): La España del Cid, 2 vols. Madrid.

MIGUEL MORA, C. de (2000): "La toma de Baza: estrategia militar y política internacional", Las Tomas: antropología histórica de la ocupación territorial del reino de Granada, J. A. González Alcantud y M. Barrios Aguilera (Eds.). Granada, pp. 28I-317.

MOLÉNAT, J.-P. (1988): "Villes et forteresses musulmanes de la région tolédane disparues après l'occupation chrétienne", Castrum III. Guerre, fortification et habitat dans le monde mediterranèen au Moyen Âge. Madrid, pp. 215-224.

MORA-FIGUEROA, L. (1994): Glosario de arquitectura defensiva militar. Cádiz.

OMAN, Ch. (1924): A History of the Art of War in the Middle Ages, 2 vols. Nueva York.

PALACIOS ONTALVA, J. S. (2005): Las fortalezas del reino de Toledo y la consolidación política del reino casteIlano (I085-I 252). Tesis doctoral, CD Rom, UAM Ediciones, Madrid. 
PALACIOS ONTALVA, J. S. (200I): "Fortalezas y Guerra Santa. Un estudio comparado de algunos aspectos de su funcionalidad en las fronteras de la Cristiandad", Espacio, Tiempo y Forma, Serie III, $H^{a}$ Medieval. No I4. Madrid, pp. 193-217.

PORRES MARTÍN-CLETO, J. (197I): Historia de las calles de Toledo, 2 vols. Toledo.

PORRES MARTíN-CLETO, J. (Ed.) (1993): Los Anales Toledanos I y II. Toledo.

PULGAR, F. del (1943): Crónica de los Reyes Católicos, J. de Mata Carriazo (Ed.), 2 vols. Madrid.

RADES Y ANDRADA, F. de (I572): Chronica de las tres Órdenes y Cauallerias de Santiago, Calatrava y Alcántara. Toledo.

RASSOW, P. (1929): "Urkunden Kaiser Alfons'VII. von Castilien (I | 26-| | 55)", Archiv für Urkundenforschung. XI. pp. 66- 137.

REILLY, B. F. (1989): El reino de León y Castilla bajo el rey Alfonso VI, 1065-I 109. Toledo.

RODRÍGUEZ PICAVEA, E. (1994): Las Órdenes Militares en la frontera. La contribución de las Órdenes a la delimitación de la jurisdicción territorial de Castilla en el siglo XII. Madrid.

SÁNCHEZ BELDA, L. (Ed.) (1950): Chronica Adefonsi Imperatoris. Madrid.
SOUTO, J. A. (1987): "Un aspecto concreto de las campañas omeyas contra la Marca Superior de al-Andalus: el campamento de 'Abdarrahm?n III ante Zaragoza (935-937). Observaciones a propósito de una hipótesis", Boletín de la Asociación Española de Orientalistas. Vol. XXIII. Madrid, pp. 333-346.

SOUTO, J. A. (1992): "Sistemas defensivos andalusíes: notas acerca de la defensa militar de la Zaragoza omeya", Actas del III Congreso de Arqueología Medieval Española. Vol. II. Oviedo, pp. 275-286.

SOUTO, J. A. ( 1996): "Obras constructivas en al-Andalus durante el gobierno de 'Abd al-Rahmān III según el volumen V del Muqtabis de Ibn Hayyān", Qurtuba. Estudios Andalusíes. N I. Córdoba, pp. 193-206.

SPEIGHT, S. (1992): "Castle Warfare in the Gesta Stephani", Château Gaillard, Études de castellologie médiévale. Actes du colloque internacional tenue à Graz (Autriche). XIX. Caen, pp. 269-274.

TORRES BALBÁS, L. (1985): Ciudades hispanomusulmanas. Madrid.

'UDRT̄, al- (1965): Nusūs 'an al-Andalus min Kitāb Tarsì al-ajbār, A. A. al-Ahwānī (Ed.), Madrid, 1965.

VIOLLET-LE-DUC, E. (1924): Dictionnaire raisonné de l'architecture française du Xle au XVle siècle, 10 vols. París. 


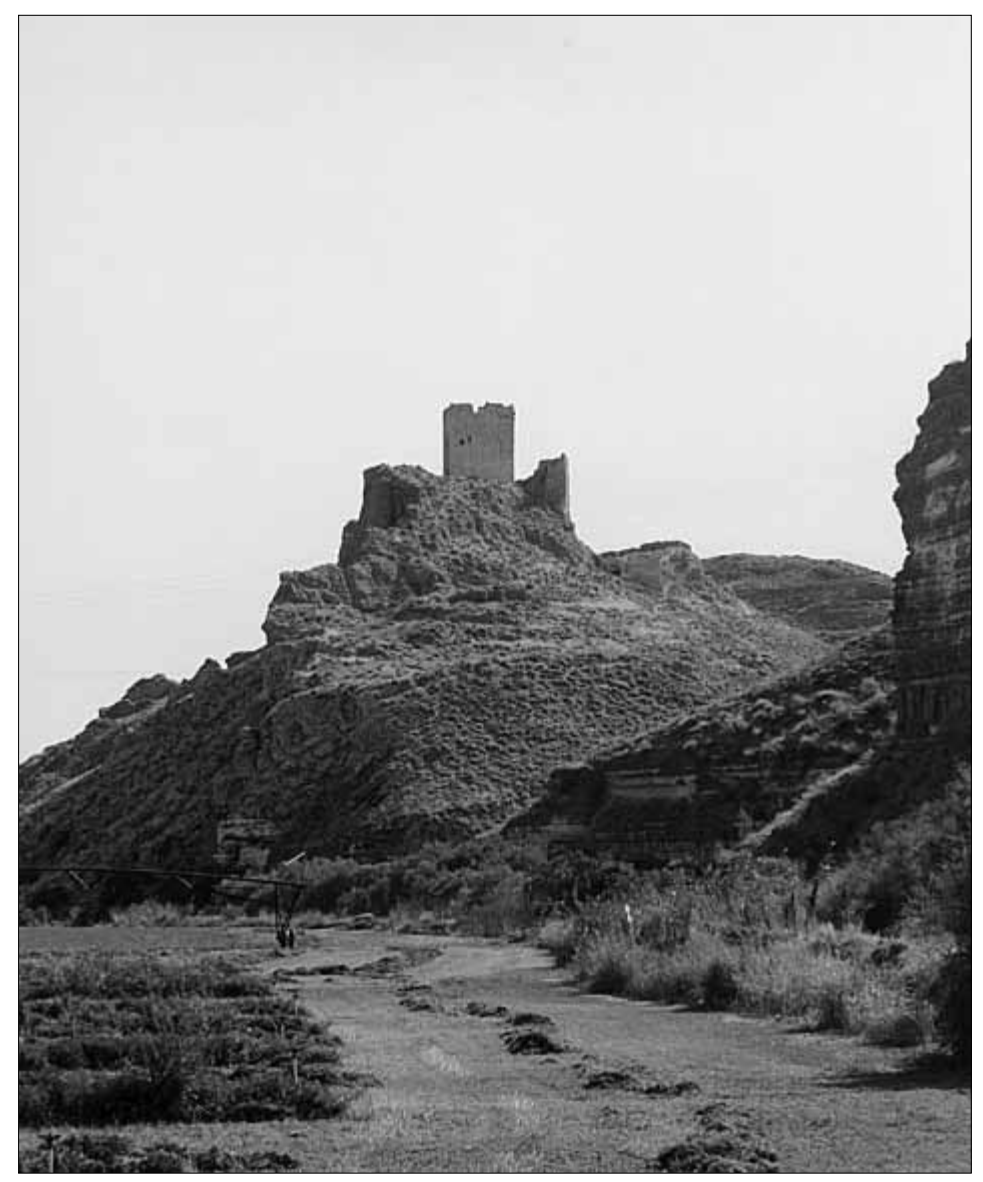

Lam. I. Emplazamiento

del castillo de Oreja.

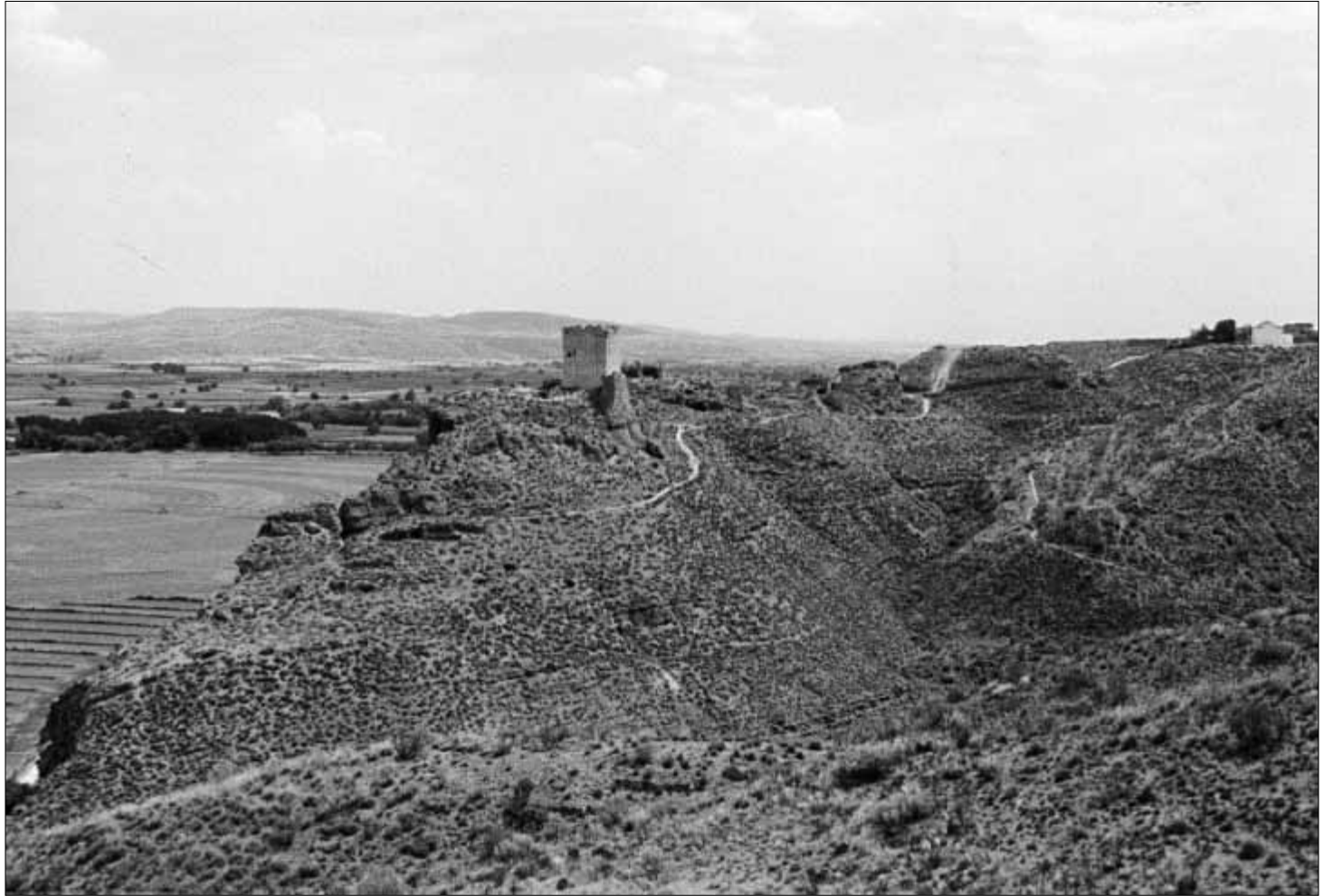

Lam. 2. Otro aspecto de la ubicación de la fortaleza de Oreja desde el lugar donde pudo estar emplazado el padrastro construido por Alfonso VII para su conquista. 


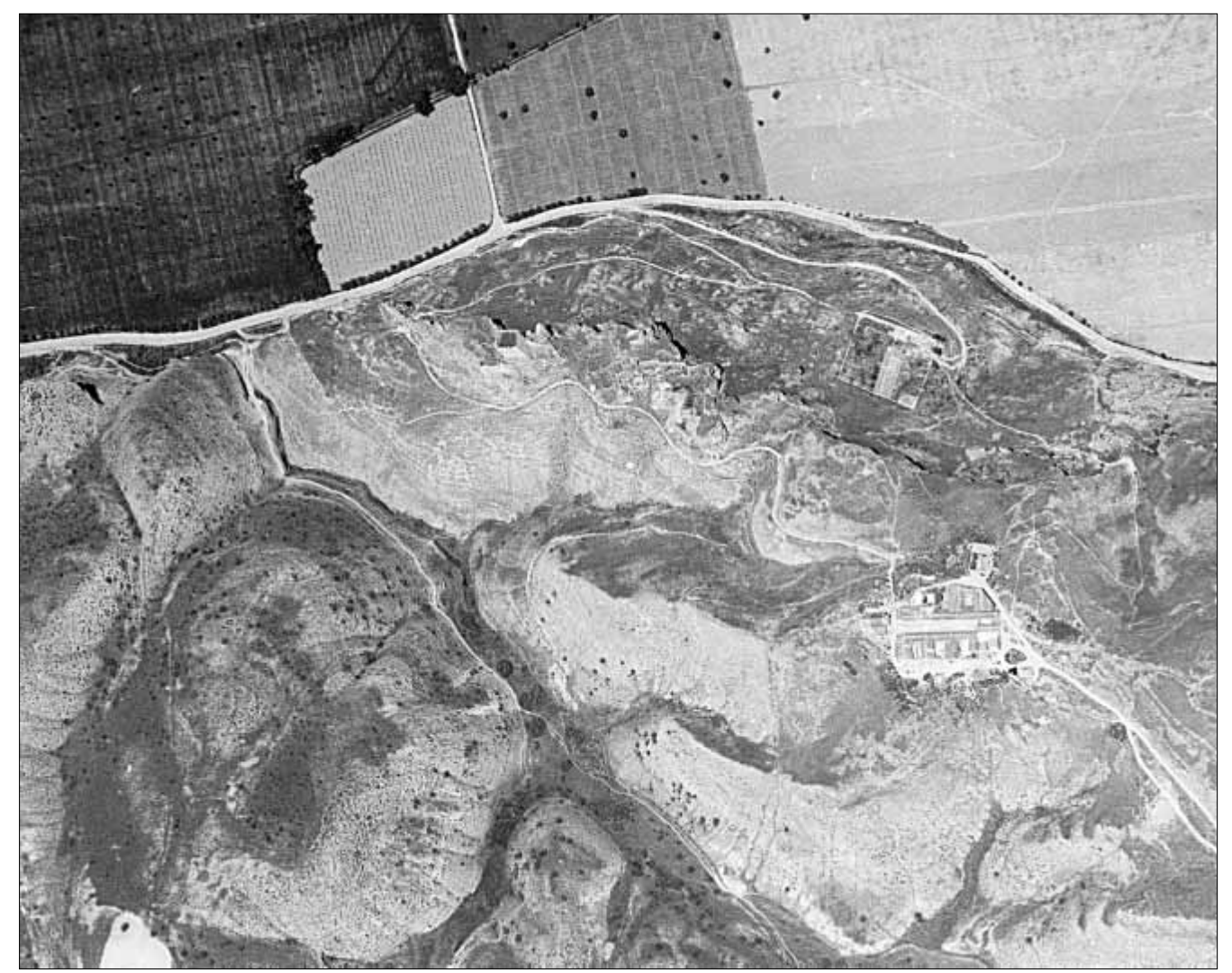

Lam. 3. Imagen aérea de Oreja. Se indica el posible emplazamiento del padrastro construido para su conquista en / 39.

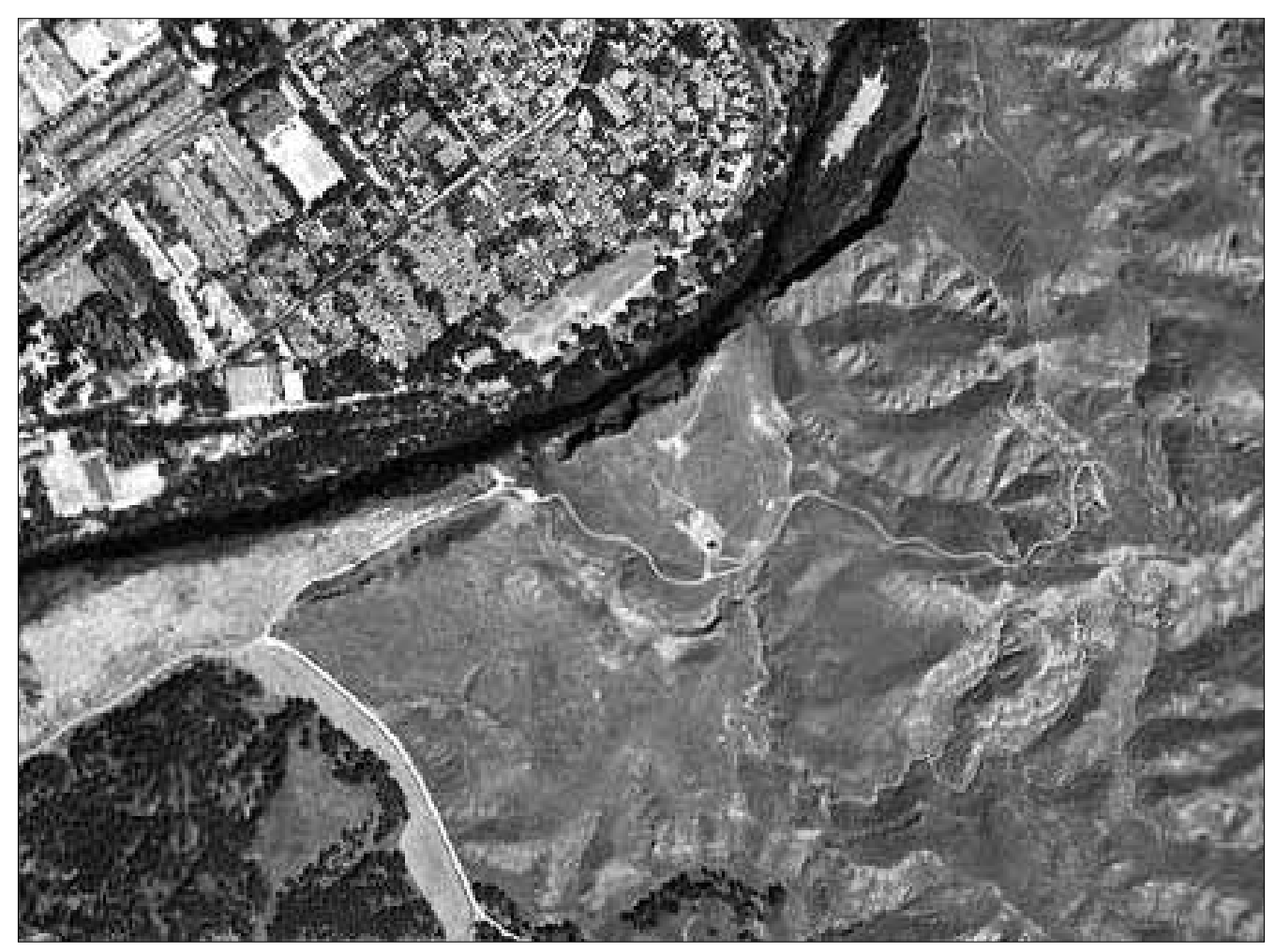

Lam. 4. Vista aérea de Alcalá la Vieja. 


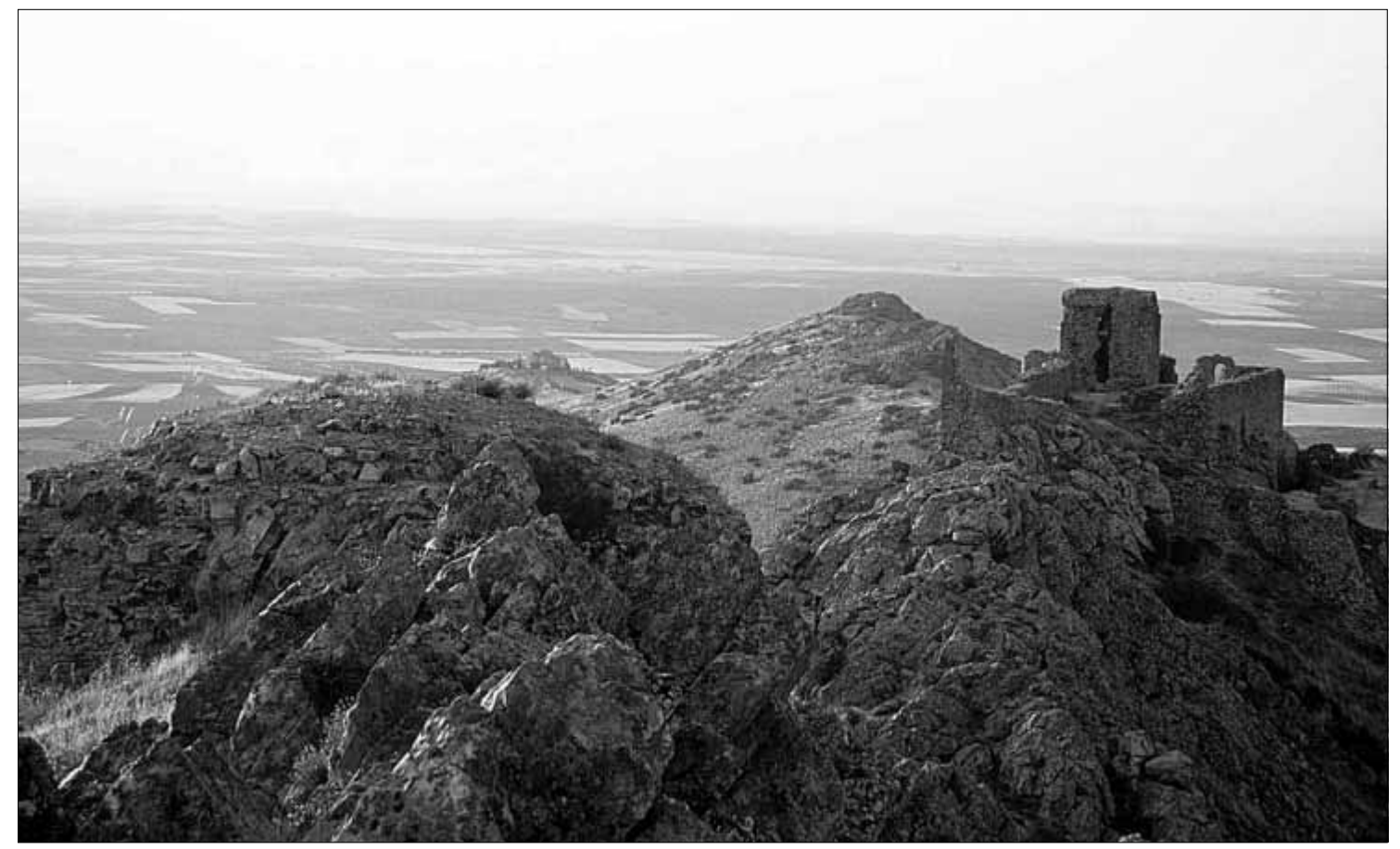

Lam. 5. Aspecto de la fortaleza de Mora desde la cota $967 \mathrm{~m}$.

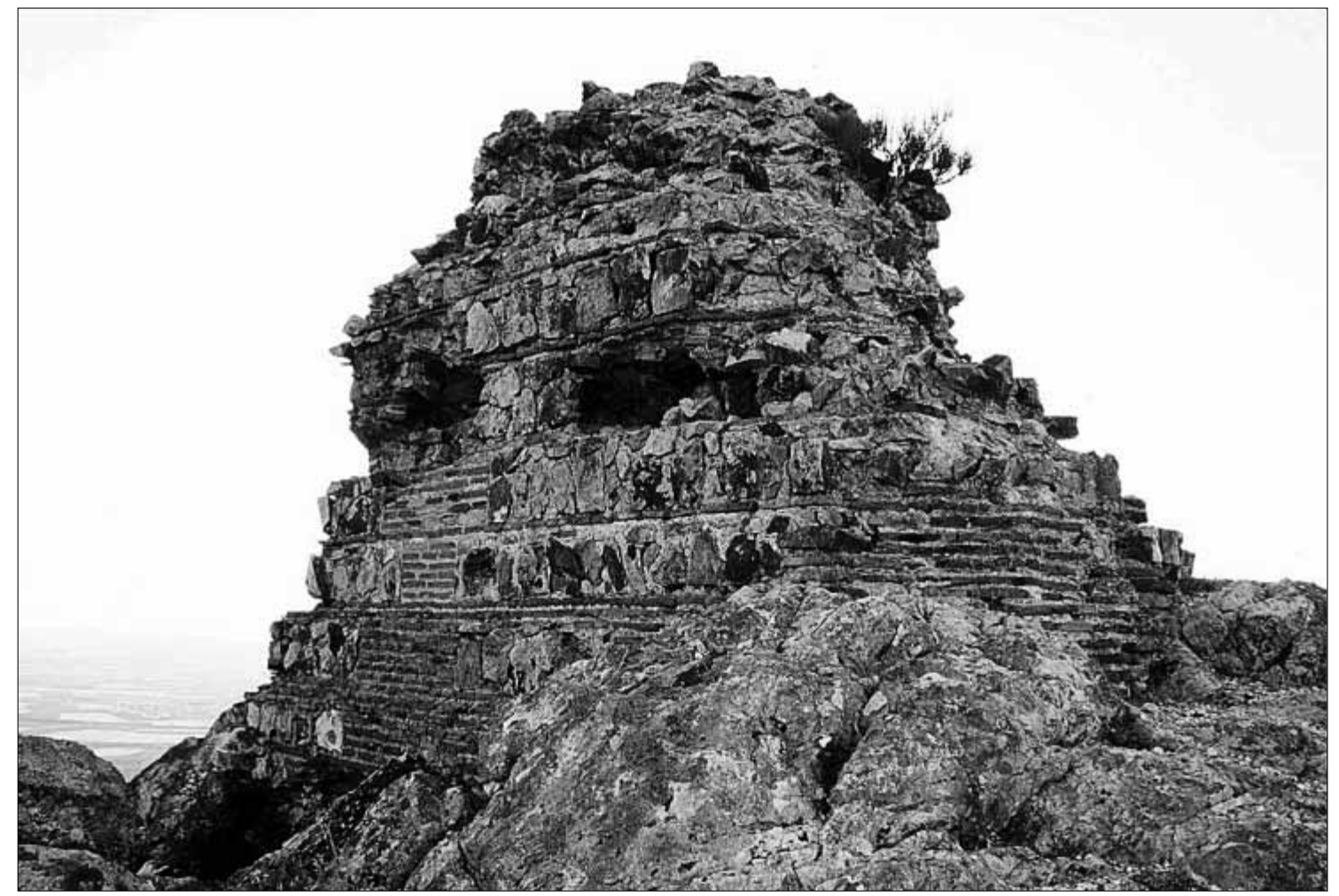

Lam. 6. Restos de estructuras con aparejo toledano ubicados en la cota $967 \mathrm{~m}$. 


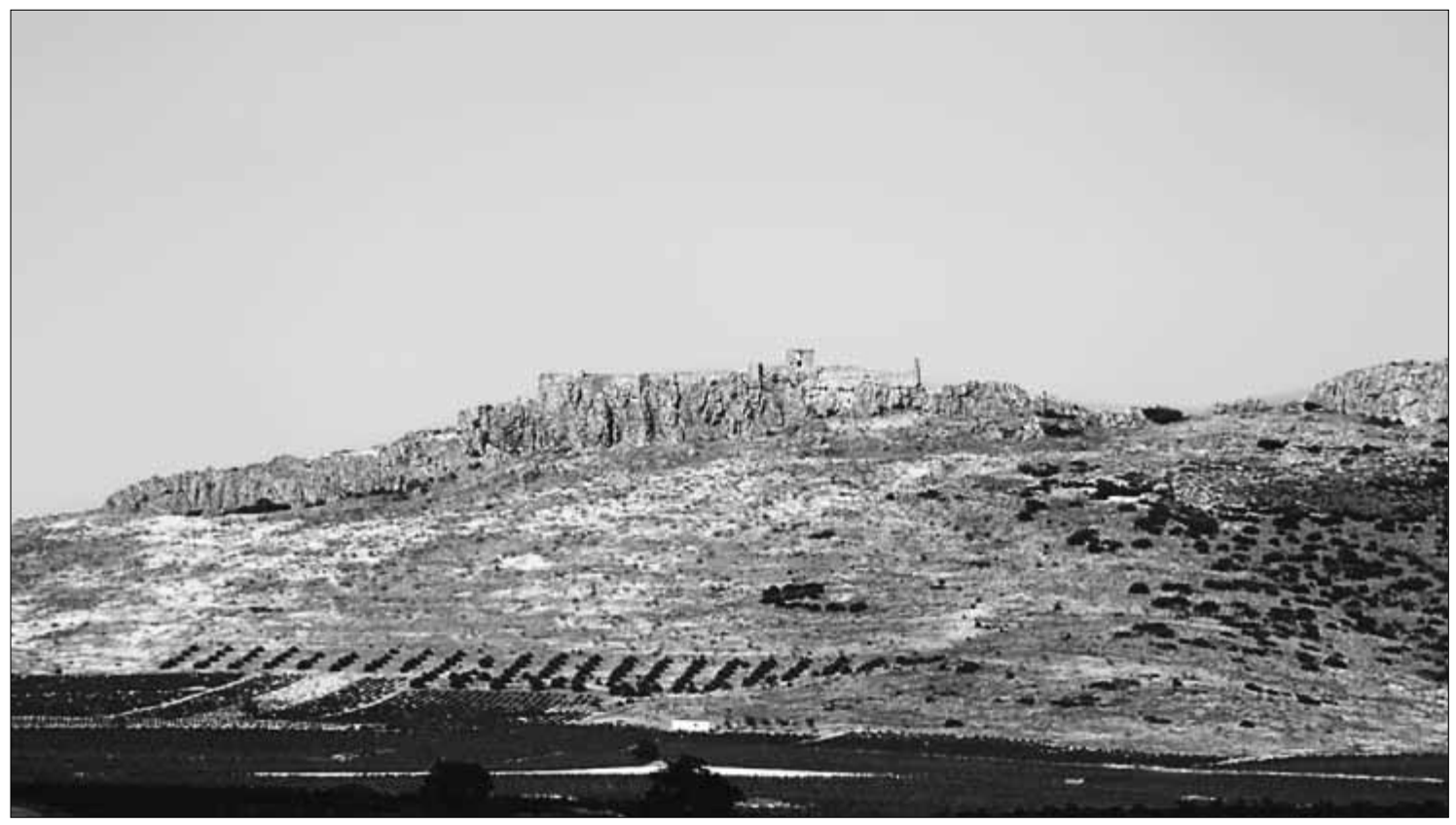

Lam. 7. Vista general de las fortificaciones de Mora.

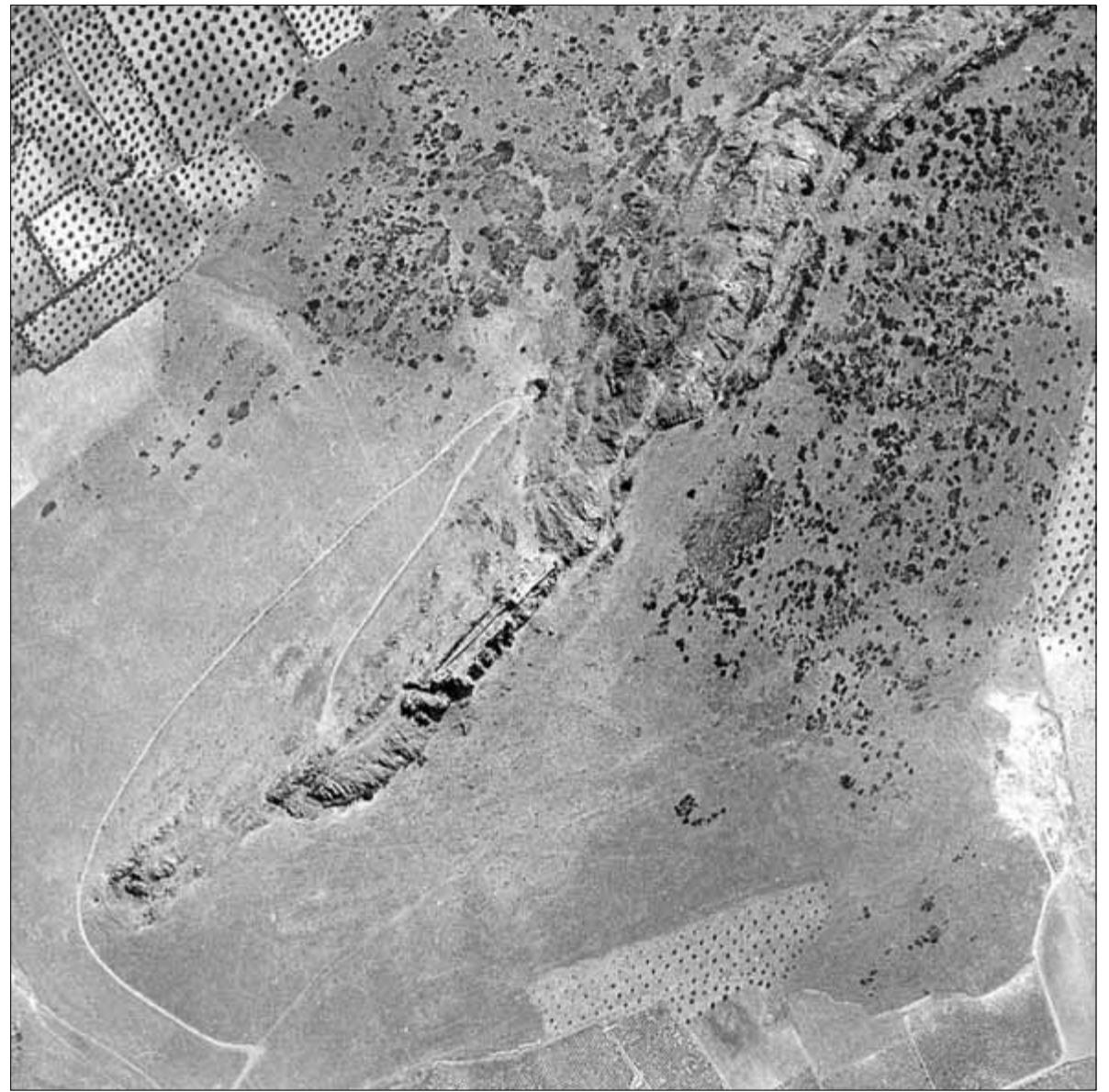

Lam. 8. Imagen aérea de Mora. 


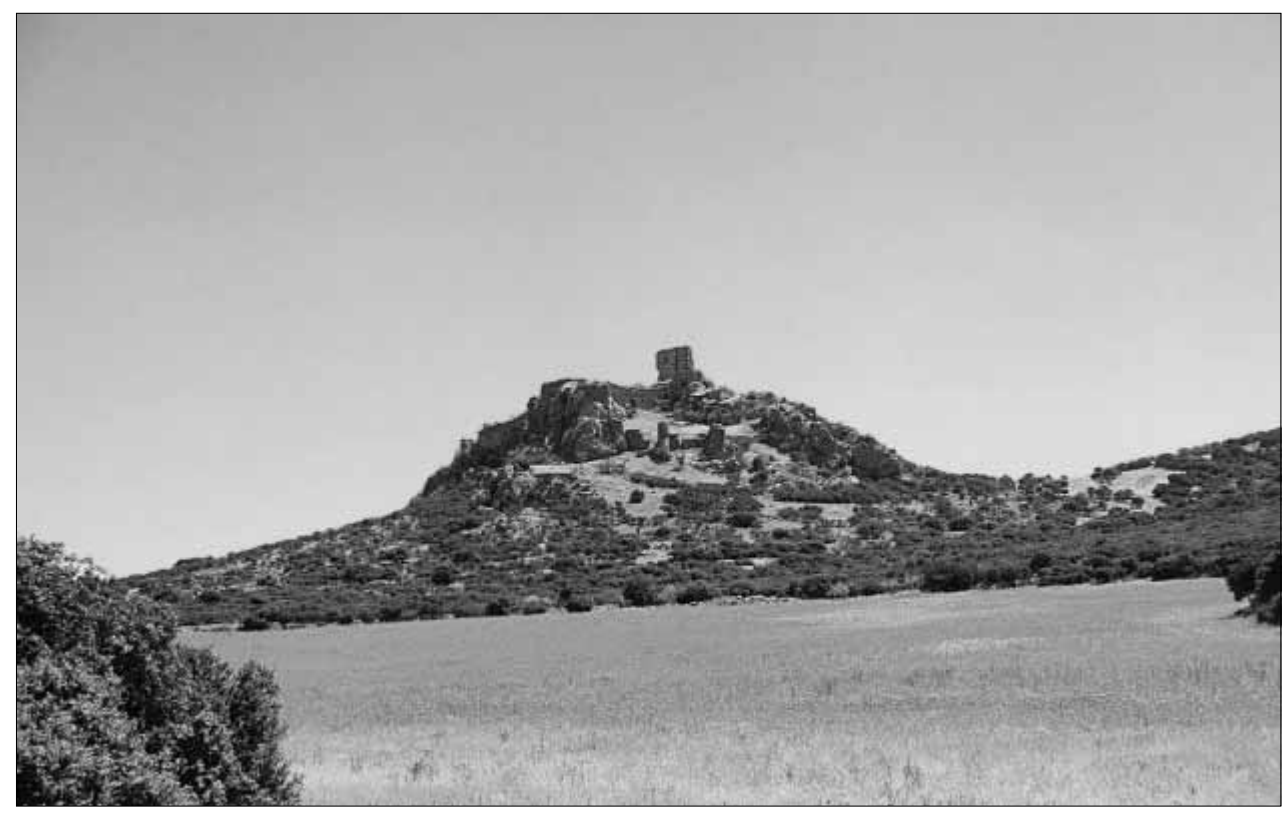

Lam. 9. El castillo de Salvatierra desde el llano que separa esta fortaleza del vecino propugnáculo de Calatrava la Nueva.

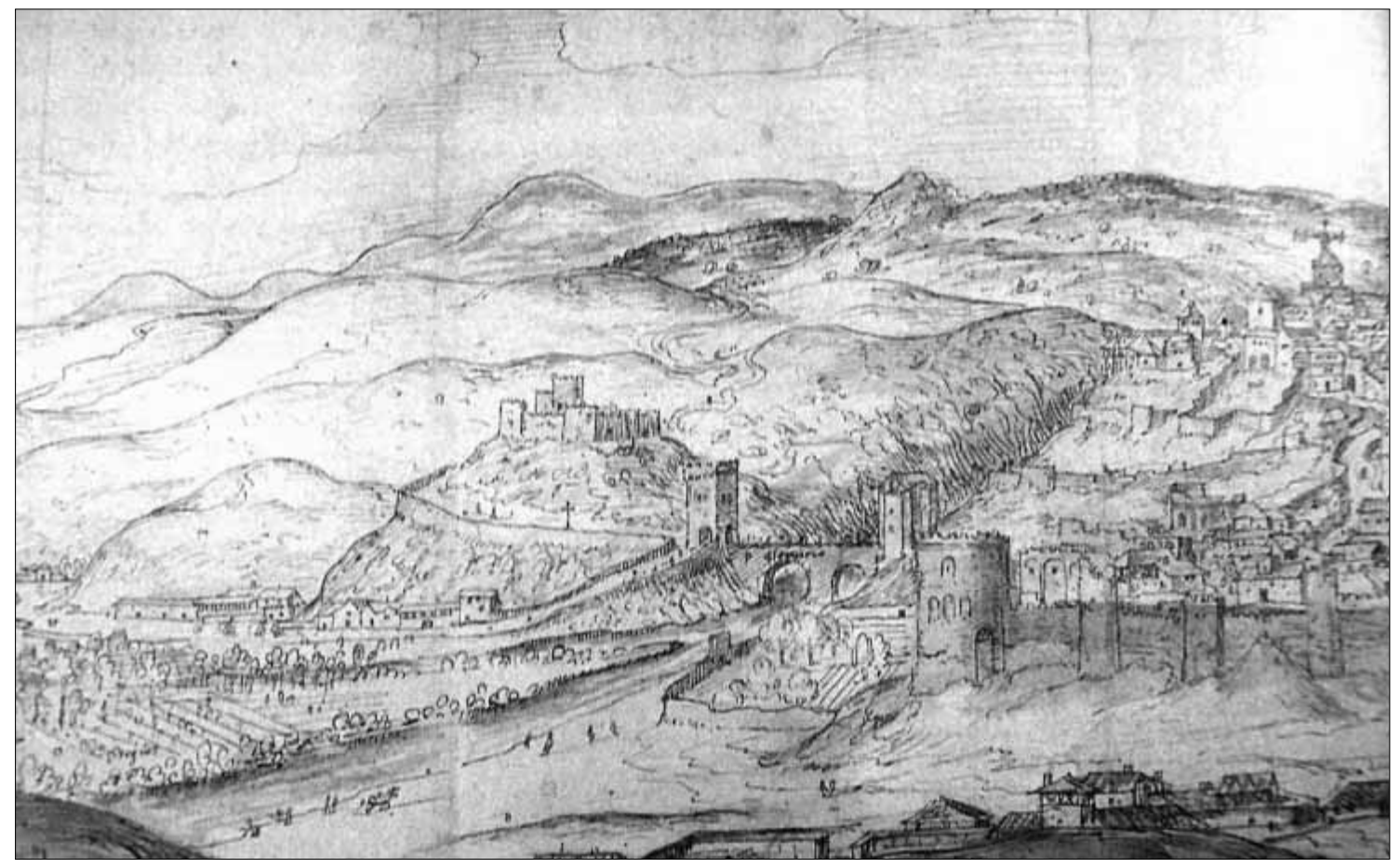

Lam. I0. Dibujo tomado de la vista de Toledo de Anton Van der Wyngaerde en la que se representa el castillo de San Servando frente al Puente de Alcántara. 


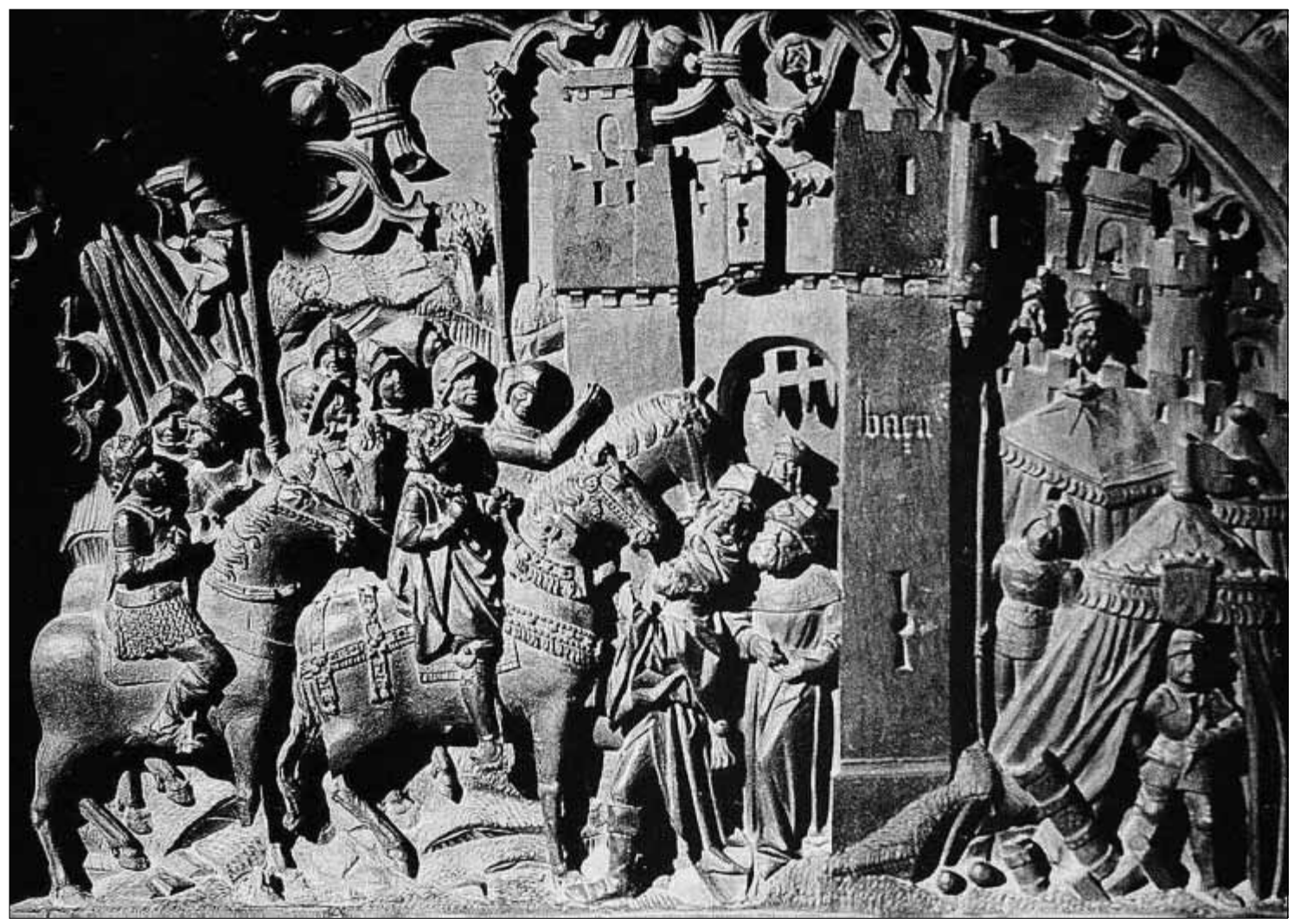

Lam. I I. Reprsntación de la conquista de Baza en la sillería de la catedral de Toledo. 